\title{
Design, Synthesis, and Biological Evaluation of Novel 5-Substituted-2-(3,4,5-trihydroxyphenyl)-1,3,4-oxadiazoles as Potent Antioxidants
}

\author{
Amgad M. Rabie*, Atif S. Tantawy, Sahar M. I. Badr \\ Department of Pharmaceutical Organic Chemistry, Faculty of Pharmacy, Mansoura University, Mansoura 35516, Egypt
}

\begin{abstract}
A novel series of 5-(5-substituted-1,3,4-oxadiazol-2-yl)benzene-1,2,3-triols (3n-z) was designed, synthesized, and evaluated for its potential antioxidant activities. Structural modifications at position 5 of the 1,3,4-oxadiazole scaffold (linked to a fixed antioxidant 3,4,5-trihydroxyphenyl moiety at position 2 of the ring) was expected to give new 1,3,4-oxadiazole derivatives with a wide spectrum of biological antioxidant activities. Undoubted elucidation and full confirmation of the chemical structures of all the newly synthesized compounds were accomplished using the spectroscopical and elemental analyses. The pharmacological screening for evaluation of the antioxidant activity of these new thirteen target 5-substituted-2-(3,4,5-trihydroxyphenyl)-1,3,4-oxadiazoles (3n-z) was done by using two of the most common in vitro antioxidant assays. The results of both assays showed that compounds $\mathbf{3} \mathbf{w}, \mathbf{s}, \mathbf{u}$ (the fumaric, malonic, and citric acids-derived 1,3,4-oxadiazoles, respectively) surprisingly exhibited very high and significant antioxidant activities, and they could be very promising lead and parent compounds for the design and synthesis of new antioxidant agents by further in vivo biological evaluations, structural modifications, and computational studies.
\end{abstract}

Keywords 1,3,4-Oxadiazoles, Phenolic hydroxyl groups, Microwave-assisted synthesis, Reactive oxy(nitro)gen species, Antioxidant activities

\section{Introduction}

Antioxidants are chemical compounds that may protect cells from the damage caused by unstable molecules known as free radicals; these antioxidant substances include those of a nonenzymatic as well as an enzymatic nature [1-4]. The oxidative stress and damage, caused by the attack of excess free radicals and other ROS (reactive oxygen species)/RNS (reactive nitrogen species) (i.e., other nonradicals), is implicated in the pathogenesis and development (and also indicative) of various diseases in human, i.e., either as a primary cause or as a consequence of disease progression, specially, the chronic diseases and degenerative disorders [2,5-7], such as neurodegenerative diseases [2,3,5-14], cardiovascular diseases $[2,3,5,6,8,10,14-16]$, hepatic and pancreatic diseases $[2,3,5-8,10,14,16-18]$, renal and urological diseases $[2,5,6,8,10,14]$, respiratory diseases [2,3,6,8,10], ocular (ophthalmic) diseases [2,3,5,6,8,10,14], dermal/hair/nails diseases $[2,3,6,8,19]$, orthopedic diseases $[2,3,5,6,10]$, hematologic diseases $[2,3,6,8,14]$,

* Corresponding author:

amgadpharmacist1@yahoo.com (Amgad M. Rabie)

Published online at http://journal.sapub.org/ajoc

Copyright () 2016 Scientific \& Academic Publishing. All Rights Reserved gastrointestinal (gastroenterological) or digestive diseases $[2,3,6,8,10]$, immunological and infectious diseases $[2,3,6]$, otorhinolaryngological (ear, nose, and throat) and dental diseases $[2,3,5,8,10]$, andrological/gynecological/obstetrical (reproductive system) diseases $[2,3,6,8]$, and other (e.g., multiorgan or multisystem) diseases [2,5-10,14,16-18].

Antioxidants can be classified according to many items $[3,7,8,15]$, but, generally, they can be classified into natural antioxidants (including many enzymes such as superoxide dismutase and glutathione reductase; some vitamins such as vitamins $\mathrm{E}$ and $\mathrm{C}$; carotenoids such as carotenes and lycopene; some polyphenols such as resveratrol and silymarin; some hormones such as melatonin; some coenzymes such as ubiquinol which is the reduced form of coenzyme $\mathrm{Q}_{10}$; some inorganic nutrients/chemical elements such as selenium and copper; and various natural antioxidant compounds such as glutathione, bilirubin, and uric acid) and synthetic antioxidants (including many dietary or nutritional antioxidant supplements such as ebselen, trolox, disufenton sodium, and raxofelast; many food additives and preservatives such as propyl gallate and butylated hydroxytoluene; and other synthetic antioxidant medicines) [2-4,6-8,14]. Figure 1 (below) shows the chemical structures of two of the most potent antioxidants (vitamin $\mathrm{C}$ and trolox). 
<smiles>O=C1O[C@H]([C@H](O)CO)C(O)=C1O</smiles>

Vitamin C (L-ascorbic acid)<smiles>Cc1c(C)c2c(c(C)c1O)CCC(C)(C(=O)O)O2</smiles>

Trolox (6-hydroxy-2,5,7,8-tetramethylchroman-2-carboxylic acid; a water-soluble analog of $\alpha$-tocopherol form of vitamin $E$ )

Figure 1. The chemical structures of vitamin $C$ (a very strong natural antioxidant) and trolox (a strong synthetic antioxidant)

The usefulness of the 1,3,4-oxadiazole ring as a privileged structure system in medicinal chemistry has prompted the advances of the therapeutic potentials of this system [20,21]. The compounds containing 1,3,4-oxadiazole nucleus, in addition to being very important organic reaction intermediates for molecule planning (as they undergo various chemical reactions), are one of the most biologically active classes of compounds as they possess an enormous spectrum of potent pharmacological activities [20,21]. Some researchers [22] proved and reported the antioxidant activity of 5-substituted-2-(3,4,5-trihydroxyphenyl)-1,3,4-oxadiazoles (5-(5-substituted-1,3,4-oxadiazol-2-yl)benzene-1,2,3-triols), the class to which the target compounds of this new research (compounds 3n-z) belong. For example, in 2011,
D. K. Mehta and R. Das [22] synthesized a new series of 5-furyl-2-aryl-1,3,4-oxadiazoles, the aryl substituent at position 2 of the 1,3,4-oxadiazole ring in most of them has phenolic hydroxyl groups, and one of the compounds of this new series is 5-(fur-2-yl)-2-(3,4,5-trihydroxyphenyl)-1,3, 4-oxadiazole ( $\mathbf{3}_{\text {Oxa }}$, Figure 2 ). They reported that $\mathbf{3}_{\text {Oxa }}$ possesses a comparable antioxidant activity to that of butylated hydroxytoluene or BHT (the standard antioxidant drug in their research); their research revealed that this compound is a good electron/hydrogen donor and could react with free radicals, and further structure modifications (e.g., replacement of the furan ring by other substituents) may produce compounds of better activity and less toxic effects, and these results proved the importance of 3,4,5-trihydroxyphenyl (1,2,3-trihydroxyphenyl) group for the antioxidation effect of 3,4,5-trihydroxyphenyl derivatives of 1,3,4-oxadiazoles. Based on these previous findings, we report here the synthesis of a new series of 5-substituted-2-(3,4,5-trihydroxyphenyl)-1,3,4-oxadiazoles (compounds 3n-z) with the objective to study the effect of changing the substitution at position 5 of the 1,3,4-oxadiazole scaffold on the antioxidant activities of these new target compounds.

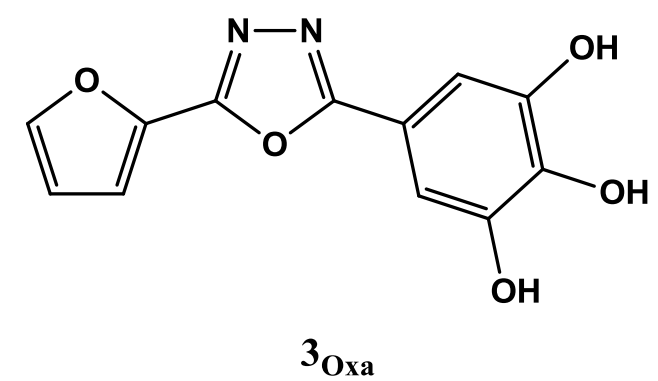

Figure 2. The chemical structure of the new antioxidant 5-(fur-2-yl)-2(3,4,5-trihydroxyphenyl)-1,3,4-oxadiazole (3 $\mathbf{3}_{\text {Oxa }}$ ) synthesized by D. K. Mehta and R. Das

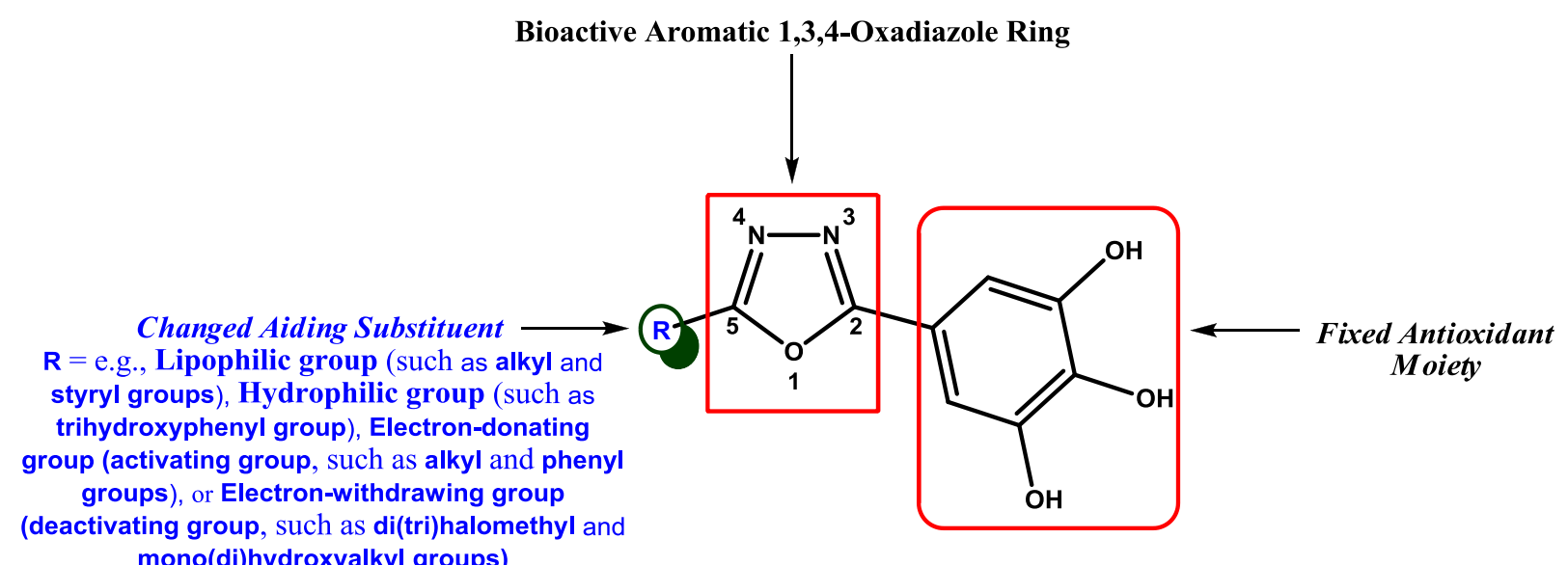

Figure 3. The Proposed general antioxidant 2,5-disubstituted-1,3,4-oxadiazole model 
In order to construct a good general antioxidant 2,5-disubstituted-1,3,4-oxadiazole model, to solve the previous literature problems associated with the use of known antioxidants specially those of the heterocyclic type, a general structural formula was firstly designed and given the number or general code 3 (Figure 3). This proposed antioxidant 2,5-disubstituted-1,3,4-oxadiazole structural model consists of three important complementary parts (i.e., three parts acting in a complementary way to give the best antioxidant activities expected), which are:

a- Bioactive Aromatic 1,3,4-Oxadiazole Ring: Many of the compounds containing the bioactive 1,3,4-oxadiazole ring (the scaffold and the main part in this model) efficiently exhibit electron donor-acceptor properties, specially when an EDG (electron-donating group) is attached to this ring, as the introduction of EDGs into the electron-withdrawing heterocyclic 1,3,4-oxadiazole ring affords excellent electron donor-acceptor compounds that are easily both oxidized and reduced (i.e., having excellent antioxidant activities by being easily oxidized by oxidants which include ROS/RNS and all other free radicals) [21]. 1,3,4-oxadiazole moiety traps free radicals and ROS/RNS by potential conjugation of the aromatic structure, in addition, it is characterized by many unique properties that are not collectively present in most other ring systems, such as acting as a hydrogen-binding domain (this greatly increases the antioxidant properties of the compounds containing it) [20-22]. All the useful properties of 1,3,4-oxadiazole ring collectively have dramatic aiding effects on the net antioxidant biological activities of the ring derivatives and this helps to reach the optimal levels.

b- Fixed Antioxidant Moiety (3,4,5-Trihydroxyphenyl Group): It was very important in the design of this antioxidant model to have a fixed antioxidant moiety at any carbon atom of the two carbons (i.e., at position 2) of the 1,3,4-oxadiazole ring that is not changed through all the compounds of this series (1,3,4-oxadiazoles series) to establish the main moiety responsible for the occurrence of the principal in vivo redox cycle in which the oxidized form of each 1,3,4-oxadiazole derivative is much more stable (i.e., favorable and predominant) than ROS/RNS and other free radicals (i.e., than most active in vivo oxidants). This group moiety was chosen to have electronegative heteroatoms that are similar to the centered electronegative heteroatom of the heterocyclic 1,3,4-oxadiazole ring (i.e., oxygen (O) atoms), and as a result, 3,4,5-trihydroxyphenyl group was chosen for this 1,3,4-oxadiazoles series. The polyhydroxyphenolic moiety (i.e., the phenolic hydroxyl $(\mathrm{OH})$ groups) has very strong antioxidant properties as it characterizes by donating its hydrogens (or, first, giving an electron, then, the proton) to any oxidant or radical, to catch it, very easily (i.e., it is a very good hydrogen donor) [22-25].

c- Changed Aiding Substituent $(\boldsymbol{R})$ : An important part, which has a complementary role in increasing the antioxidant activities of this model, is the changeable aiding moiety or substituent (R) at position 5 (i.e., at the other carbon) of the 1,3,4-oxadiazole scaffold. The main function of this aiding substituent $\mathrm{R}$ is to increase the net total antioxidant activities of the target compounds, directly, through helping their pharmacodynamic properties (i.e., through giving an additive antioxidant effect to the activity of the original parent 2-(3,4,5-trihydroxyphenyl)-1,3, 4-oxadiazole compound and/or aiding the mechanism of the antioxidant action of the original parent 2-(3,4, 5-trihydroxyphenyl)-1,3,4-oxadiazole compound) and/or, indirectly, through helping their pharmacokinetic parameters to reach the required optimal values according to the need, target site(s) of administration, and target human organs (e.g., by increasing their lipophilicity/ hydrophilicity, rate of absorption, and bioavailability). The chemical structures of all the $\mathrm{R}$ groups of the thirteen target compounds (3n-z) are demonstrated in Table 1.

In view of the above-mentioned introductory facts, it is concluded that 1,3,4-oxadiazole scaffold and 1,2,3-trihydroxyphenyl (3,4,5-trihydroxyphenyl) moiety have been known to have antioxidant properties and, therefore, according to "the combination principles", if an aromatic 1,3,4-oxadiazole ring is directly linked with a 3,4,5-trihydroxyphenyl group at position 2 of the ring and with an aiding group at position 5 of the ring, the produced 2,5-disubstituted-1,3,4-oxadiazoles (1,3,4-oxadiazole scaffold derivatives) should be or are expected to be capable of scavenging free radicals, ROS, RNS, and all other types of oxidants in a potent ideal manner (i.e., potent antioxidants).

\section{Results and Discussion}

\subsection{Chemical Synthesis}

The synthetic scheme of this research (Scheme 1, illustrated below) was adopted for the synthesis of the target compounds of the 1,3,4-oxadiazole series (compounds 3n-z). Ethyl 3,4,5-trihydroxybenzoate (ethyl gallate, $\mathbf{1 n z}$ ) is the first intermediate compound synthesized in order to reach the final target compounds $\mathbf{3 n - z}$ (it is an old ester which is conventionally synthesized from 3,4, 5-trihydroxybenzoic or gallic acid by direct esterification), while the second intermediate compound is 3,4 , 5-trihydroxybenzohydrazide (galloyl hydrazide, 2nz) which is either conventionally synthesized from the corresponding ester 1nz, or directly synthesized from the corresponding carboxylic acid (i.e., gallic acid) by MW-assisted (microwave-assisted) method without passing through the esterification step. The final step in this scheme is the oxidative cyclodehydration reaction which is used for the synthesis of all the different new thirteen target 5-(5-substituted-1,3,4-oxadiazol-2-yl)benzene-1,2,3-triols (5-substituted-2-(3,4,5-trihydroxyphenyl)-1,3,4-oxadiazoles, final products 3n-z). All these synthetic steps are discussed below in details. 
Table 1. List of the chemical structures, shown in blue, of all the diverse R substituents present in the target 1,3,4-oxadiazoles (3n-z)

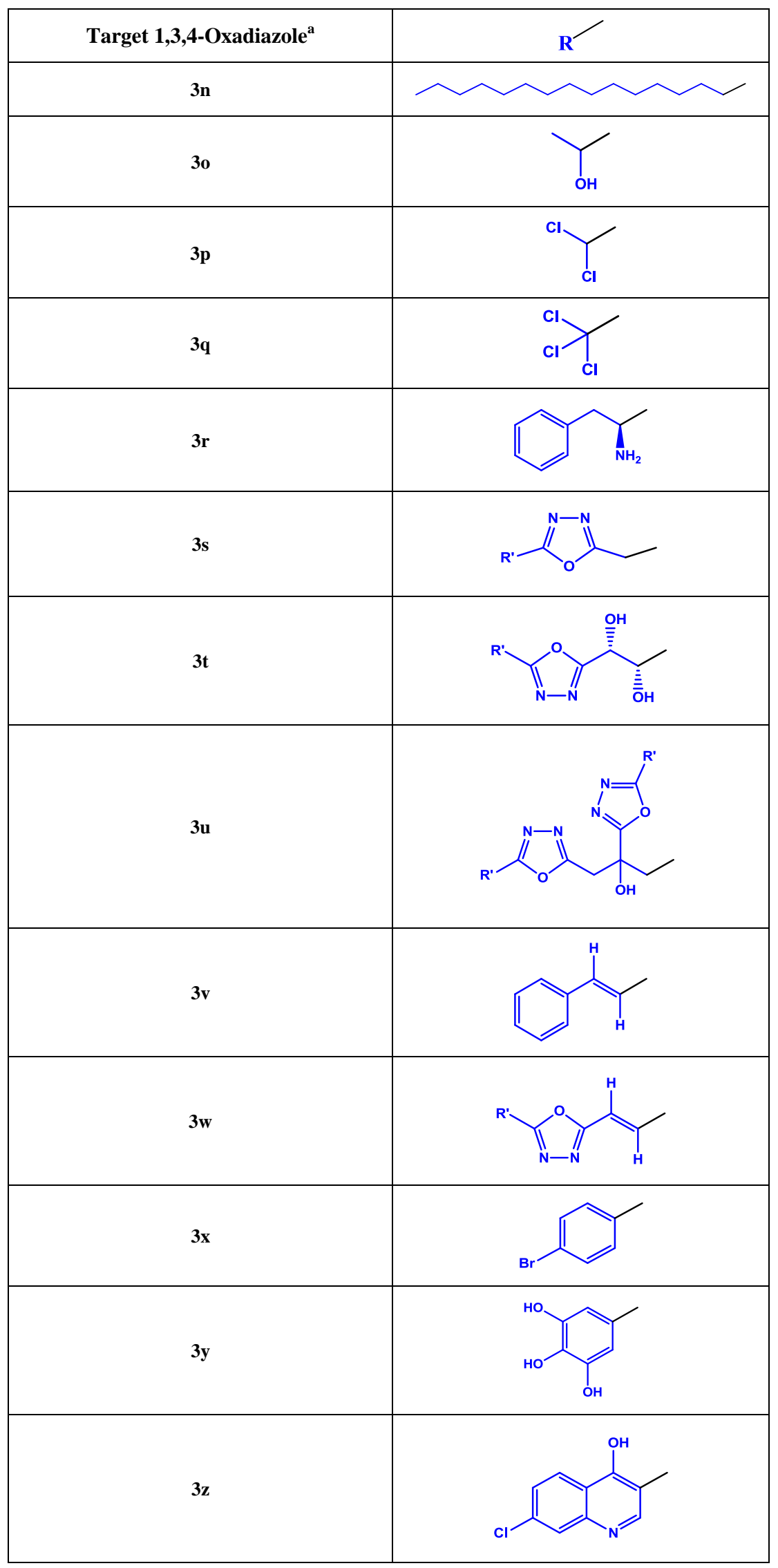

${ }^{\mathrm{a}} \mathrm{R}^{\prime}=3,4,5$-trihydroxyphenyl. 


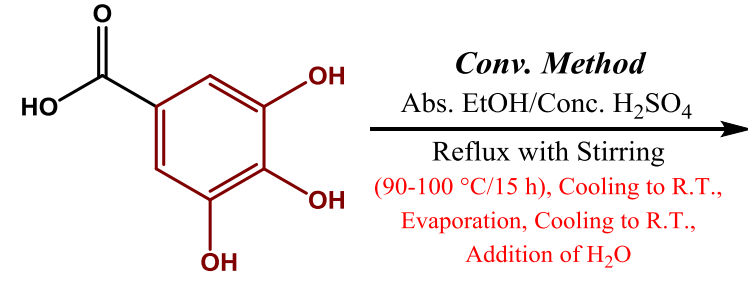

Gallic Acid

(Starting Material)

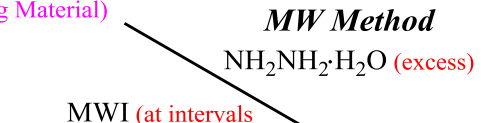

MW Method

of $30 \mathrm{~s}$ for $2 \mathrm{~min}$ at $800 \mathrm{~W}$

at $2.45 \mathrm{GHz}$ ), Cooling to $-20^{\circ} \mathrm{C}$,

Lyophilization at $-50^{\circ} \mathrm{C}$<smiles>[R]C(=O)O</smiles>

S.C.A.

(of various types; it may be natural/synthetic,

mono/di/tricarboxylic, aliphatic/aromatic,

saturated/unsaturated, homo/heterocyclic, side/long-

chain, amino/fatty, hydroxy [mono/dihydroxylated

or trihydroxyphenolic $] /$ halogenated

[monobrominated or mono/di/trichlorinated],

symmetrical/asymmetrical, mixed, ... etc.)

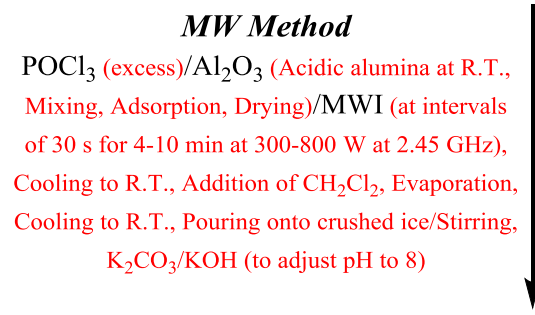<smiles>[R]c1nnc(-c2cc(O)c(O)c(O)c2)o1</smiles>

5-Substituted-2-(3,4,5-trihydroxyphenyl)-1,3,4-oxadiazole

(Target End Products, $3 n-z)$

73.0-94.0\% (Conv.), $95.0-99.2 \%$ (MW)

Scheme 1. Synthesis of the target 5-(5-substituted-1,3,4-oxadiazol-2-yl)benzene-1,2,3-triols (3n-z)

\subsubsection{Conventional Synthesis of Ethyl Gallate (1nz)}

1nz was synthesized by using the normal conventional esterification reaction of anhydrous gallic acid with absolute $\mathrm{EtOH}$ (ethanol) as the alcohol and Conc. $\mathrm{H}_{2} \mathrm{SO}_{4}$ (concentrated sulfuric acid) as the catalyst (strong dehydrating agent). EtOH acts, also, as the refluxing solvent for this reaction at about $90-100{ }^{\circ} \mathrm{C}$ for $15 \mathrm{~h}$ (hours). This reaction was reported by many scientists and researchers like Shigeki Takaoka et al. [26] and Krishna C. Majumdar et al. [27] (all in 2009). There are some other methods for the synthesis of $\mathbf{1 n z}$ from gallic acid, e.g., the direct method of Ambika et al. [28] and the indirect method of Kosuke Dodo et al. [29] (both methods were reported in 2008), but they are expensive, complicated, and less common.

\subsubsection{Synthesis of Galloyl Hydrazide (2nz)}

2nz was synthesized by using the hydrazinolysis reaction which is suggested to proceed via the normal nucleophilic substitution mechanism [30] in which $\mathrm{NH}_{2} \mathrm{NH}_{2}$ (hydrazine) molecule, being a good nucleophile, attacks the electrophilic carbon of the carbonyl group of either the corresponding ester (1nz) or the corresponding carboxylic 
acid (gallic acid). This synthetic step was achieved in this current research through either one of the following two methods:

a- Common Conventional Method (from the corresponding ester): It is the known traditional method for the synthesis of $\mathbf{2 n z}$ in which the corresponding ester (mainly, the ethyl ester or 1nz) is hydrazinolyzed using $\mathrm{NH}_{2} \mathrm{NH}_{2} \cdot \mathrm{H}_{2} \mathrm{O}$ (hydrazine hydrate) in the presence of EtOH as the refluxing solvent for the reactants (for $6 \mathrm{~h}$ in this current research). Generally, many of the references that reported this method in the literature mentioned the use of the ethyl ester for this reaction [22,31-38], some others mentioned the use of the propyl ester [39-46], while few others mentioned the use of the methyl ester [33,47-50].

The ethyl ester 1nz was preferred, in this research, over the famous propyl gallate ester (and all other gallate esters in general), i.e., it is the ester of choice for this hydrazinolysis reaction, due to many reasons, such as providing the reaction with an internal autosolvent through giving EtOH as a byproduct of the reaction which could be condensed, recovered, and reused as a solvent for the reaction mixture, so less volume of the primary original EtOH would be used leading to reduced reaction costs, unlike the propyl ester which would give propanol instead; also ethyl group is a much better leaving group than the longer propyl group in this reaction, because it is easier to leave than the propyl one which is heavier than it, so a faster reaction with better yield would be obtained; and, in addition to these advantages of using it over the propyl gallate, the ethyl ester is mostly the first common choice, for this type of reactions (i.e., for condensation reactions).

b- New Green MW Method (from the corresponding carboxylic acid): It is a newly discovered and designed solventless method as it needs only the two reactants, gallic acid and $\mathrm{NH}_{2} \mathrm{NH}_{2} \cdot \mathrm{H}_{2} \mathrm{O}$, with no need for any solvents, catalysts, inert supports, or other reagents [35]. Here, the reaction is directly made on the corresponding original carboxylic acid (gallic acid) without passing through the first step of ester synthesis, so it is just one fast greener step (unlike the previous conventional method which includes two slow hazardous separate steps, firstly, to form the ester $\mathbf{1 n z}$ from gallic acid, then to form the hydrazide $\mathbf{2 n z}$ from the ester 1nz) with very high excellent rates of saving time, energy, and money (in addition, it is environmentally safe) relative to the traditional method of conventional heating (Table 2 below shows a detailed comparison between both the conventional and MW methods for $\mathbf{2 n z}$ synthesis beginning from gallic acid).

Table 2. Comparative assessment of Conv. (conventional) method versus MW method of synthesis of galloyl hydrazide (2nz) from gallic acid (anhydrous) using many of the various green chemistry matrices (measures and metrics) with their improvement degrees in the MW method relative to the Conv. one

\begin{tabular}{|c|c|c|c|}
\hline Matrix & Conv. Method & MW Method & Improvement \\
\hline Overall Yield & $90.0 \%$ & $98.2 \%$ & $8.2 \%$ increase (more productive method) \\
\hline Overall Heating Time & $21 \mathrm{~h}(75600 \mathrm{~s})$ & $120 \mathrm{~s}$ & 630 times less (time-saving method) \\
\hline Number of Steps & $\begin{array}{l}\text { Two (two different separate } \\
\text { reactions) }\end{array}$ & One (one-pot method) & $50 \%$ decrease (simpler and cheaper method) \\
\hline Solvent & Present (in the second step) & Absent & Solvent-free or solventless greener method \\
\hline Alcohol for Esterification & Present (in the first step) & $\begin{array}{l}\text { Absent (no need for this } \\
\text { step) }\end{array}$ & One-pot alcohol-free greener method \\
\hline Catalyst and Dehydrating Agent & $\begin{array}{l}\text { Present (Conc. } \mathrm{H}_{2} \mathrm{SO}_{4} \text { in the } \\
\text { first step) }\end{array}$ & $\begin{array}{l}\text { Absent (no need for this } \\
\text { step or dehydrating agent) }\end{array}$ & More efficient simpler greener method \\
\hline Energy Consumption $(\mathrm{KWh})^{a}$ & 42 & $0.02667^{\mathrm{b}}$ & About 1575 times less (energy-saving method) \\
\hline E-Factor ${ }^{c}$ & 4.8 & 0.2 & $\begin{array}{l}95.83 \% \text { decrease (in the total waste produced in } \\
\mathrm{Kg} \text { over the production of } 1 \mathrm{Kg} \text { of the product) }\end{array}$ \\
\hline Atom Economy $(\%)^{d}$ & 69.16 & 83.64 & $\begin{array}{l}14.48 \% \text { increase (in the greenness of the } \\
\text { method) }\end{array}$ \\
\hline Atom Efficiency $(\%)^{e}$ & 62.24 & 82.14 & $\begin{array}{l}19.90 \% \text { increase (in the efficiency of the } \\
\text { method) }\end{array}$ \\
\hline Carbon Efficiency $(\%)^{f}$ & 77.78 & 100.00 & $22.22 \%$ increase \\
\hline
\end{tabular}

${ }^{\text {a }}$ KWh: Kilowatt-hour(s).

${ }^{\mathrm{b}}$ Adjusted $\mathrm{P}$ (power) of MW oven for the synthesis of $\mathbf{2 n z}$, in this present work, is $800 \mathrm{~W}$.

c E-factor: Environmental factor, E-factor = mass of total waste $(\mathrm{Kg}) /$ mass of product $(\mathrm{Kg})$, the value of this factor depends on one's definition of " waste", so it varies.

${ }^{\mathrm{d}}$ Atom economy $(\%)=$ M.Wt. of product $\times 100 /($ M.Wt. of reactant $1+$ M.Wt. of reactant $2+$ M.Wt. of reactant $3+\ldots$ etc. $)$.

${ }^{\mathrm{e}}$ Atom efficiency $(\%)=\%$ overall yield $\times \%$ atom economy $\times 100$.

${ }^{\mathrm{f}}$ Carbon efficiency $(\%)=$ mass of carbon in product $\times 100 /$ total mass of carbon present in all reactants (i.e., number of moles of product $\times$ number of carbons in product / [(number of moles of reactant $1 \times$ number of carbons in reactant 1$)+($ number of moles of reactant $2 \times$ number of carbons in reactant 2$)+($ number of moles of reactant $3 \times$ number of carbons in reactant 3$)+\ldots$ etc.]. 
HPLC (high-performance liquid chromatography) analysis is used for the separation of $\mathbf{2 n z}$ from other related gallic/gallate derivatives that might be present in the crude $\mathbf{2 n z}$ in extremely minute quantities (not exceeding $1 \%$ of the total weight) as minor impurities (i.e., HPLC analysis is used for further purification and determination of purity of the crude $\mathbf{2 n z}$ produced in this work) [51]. For detection, separation, and determination (of their percentage in the total weight) of these closely related impurities from the crude 2nz, preparative HPLC and RP (reversed-phase) technique of chromatography were used (see Figure 4 and the Experimental Work for the details of the conditions and results of this procedure) [51]. Although $\mathbf{2 n z}$ is a previously synthesized and known compound, but the heating time for the hydrazinolysis reaction, solvent system of TLC (thin-layer chromatography) for monitoring the hydrazinolysis reaction ( $5 \%$ absolute $\mathrm{MeOH}$ (methanol) in $\mathrm{CH}_{2} \mathrm{Cl}_{2}$ (dichloromethane or methylene chloride) was used in this work), recrystallization solvent system, yield, color, and melting point differ from some references to others in the previous literature $[37,39-46,48,49]$, so further elucidation and confirmation of its chemical structure was accomplished in this present research using both the spectroscopical (IR, ${ }^{1} \mathrm{H}-\mathrm{NMR},{ }^{13} \mathrm{C}-\mathrm{NMR}$, and MS (mass spectroscopy)) and elemental analyses.

Unequivocal elucidation and confirmation of the chemical structure of compound $\mathbf{2 n z}$ were accomplished using both the spectroscopical (IR, ${ }^{1} \mathrm{H}-\mathrm{NMR},{ }^{13} \mathrm{C}-\mathrm{NMR}$, and MS) [52] and elemental analyses. In IR spectrum, the presence of the common characteristic absorption peaks of $\mathrm{NH}$ stretching at frequencies of 3393 and $3299 \mathrm{~cm}^{-1}$ (proving the presence of the $\mathrm{NH}_{2}$ moiety), the presence of the common characteristic absorption peak of amide $\mathrm{NH}$ stretching at a frequency of $3204 \mathrm{~cm}^{-1}$ which is slightly lower than those of $\mathrm{NH}_{2}$ moiety (proving the presence of the amide $\mathrm{NH}$ moiety), and the presence of the common strong characteristic absorption peak of amide $\mathrm{C}=\mathrm{O}$ stretching at a frequency of $1606 \mathrm{~cm}^{-1}$ (which is slightly lower than $1700 \mathrm{~cm}^{-1}$, i.e., lower than those of any other known $\mathrm{C}=\mathrm{O}$ moiety, e.g., $\mathrm{C}=\mathrm{O}$ moiety of esters and carboxylic acids, as there were not any detected peaks observed in the frequencies region of $1900-1700 \mathrm{~cm}^{-1}$ in the resulted IR spectrum; specifically proving the presence of the amide $\mathrm{C}=\mathrm{O}$ moiety) indicated the conversion of all the ester 1nz or gallic acid to the hydrazide $\mathbf{2 n z}$ (the presence of the characteristic IR peaks of the $\mathrm{N}-\mathrm{N}$ and $\mathrm{C}-\mathrm{N}$ moieties also confirmed the formation of the hydrazide) [48,52]. In ${ }^{1} \mathrm{H}-\mathrm{NMR}$ spectrum, the presence of the common characteristic singlet signal of the two protons of the primary $\mathrm{NH}_{2}$ moiety at about $2.000 \mathrm{ppm}$ (proving the presence of the primary $\mathrm{NH}_{2}$ moiety attached to the secondary amide $\mathrm{NH}$ moiety) and the presence of the common characteristic singlet signal of the proton of the secondary $\mathrm{NH}$ moiety at about $8.002 \mathrm{ppm}$ (proving the presence of the secondary NH moiety attached to both the primary $\mathrm{NH}_{2}$ moiety and the amide $\mathrm{C}=\mathrm{O}$ moiety) undoubtedly indicated the conversion of all the ester $\mathbf{1 n z}$ or gallic acid to the hydrazide $\mathbf{2 n z}$ (the absence of any characteristic signal for the proton of the $\mathrm{OH}$ group of the carboxyl moiety of gallic acid in the region above $10.0 \mathrm{ppm}$ in the spectrum was very informative giving an excellent confirmation of the disappearance and conversion of all gallic acid) $[48,52]$. In ${ }^{13} \mathrm{C}-\mathrm{NMR}$ spectrum, the presence of the common characteristic signal of the carbon of the amide $\mathrm{C}=\mathrm{O}$ moiety at $166.528 \mathrm{ppm}$ along with the absence of any specific detected signals for the carbons of Et group (proving the presence of the amide $\mathrm{C}=\mathrm{O}$ moiety of the hydrazide $\mathbf{2 n z}$ and the absence of the Et moiety of the ester 1nz) also indicated the conversion of all the ester $1 \mathbf{n z}$ to the hydrazide $\mathbf{2 n z}$ (the presence of the characteristic signals for the differently substituted carbons of the benzene ring was an additional confirmation of the presence of $\mathbf{2 n z}$ ) [48,52]. In MS chart, the final and base peak detected with $100 \%$ relative intensity was at $\mathrm{m} / \mathrm{z}$ equals 185 (without any detected peaks at $\mathrm{m} / \mathrm{z}$ equals $169-171$ or over 185 ) indicated the conversion of all the ester $\mathbf{1 n z}$ or gallic acid, which have molecular weights of 198.17 and 170.12, respectively, to the hydrazide $\mathbf{2 n z}$ which has a molecular weight of 184.15 [52]. Elemental analyses results gave a final confirmatory assignment and verification for $\mathbf{2 n z}$ structure (results were very satisfactory as the found percentages of $\mathrm{C}, \mathrm{H}$, and $\mathrm{N}$ atoms in $\mathbf{2 n z}$ molecule were 45.64, 4.37, and 15.24, respectively, which are very close to the calculated ones, i.e., to 45.66, 4.38, and 15.21, respectively) [48]. Figures 5-8 below show four scanned copies of the four spectral charts obtained upon IR, ${ }^{1} \mathrm{H}-\mathrm{NMR},{ }^{13} \mathrm{C}-\mathrm{NMR}$, and $\mathrm{MS}$ analyses, respectively, of the sample of the synthesized compound $\mathbf{2 n z}$.

\subsubsection{Synthesis of 5-Substituted-2-(3,4,5-trihydroxyphe- nyl)-1,3,4-oxadiazoles (3n-z)}

Compounds 3n-z were synthesized by using the oxidative cyclodehydration reaction of the hydrazide $2 \mathbf{n z}$ with various starting carboxylic acids (S.C.A.) in $\mathrm{POCl}_{3}$ (phosphorus oxychloride) as the strong dehydrating agent, which is either refluxing $\mathrm{POCl}_{3}$ (conventional method) or adsorbed $\mathrm{POCl}_{3}$ (MW-assisted method) [22,31,32,34,39,47,50,53,54]. Table 3 shows the heating time (in h and min "minutes", respectively) and power (in W "watts") needed by the conventional method (method A) and MW method (method B). All compounds were synthesized in good to excellent yields ranging from 73.0 to $94.0 \%$ (conventionally) and from 95.0 to $99.2 \%$ (MW method) (see the Experimental Work for details). The designed MW method, used here, gave much better results than the conventional one (see the detailed table, Table 4 , for the comparison of MW method versus conventional one for the synthesis of 2,5-disubstituted-1,3,4-oxadiazoles from their precursors, $2 \mathbf{n z}$ and S.C.A.). 


\section{Central Laboratory} Faculty of Pharmacy Mansoura University

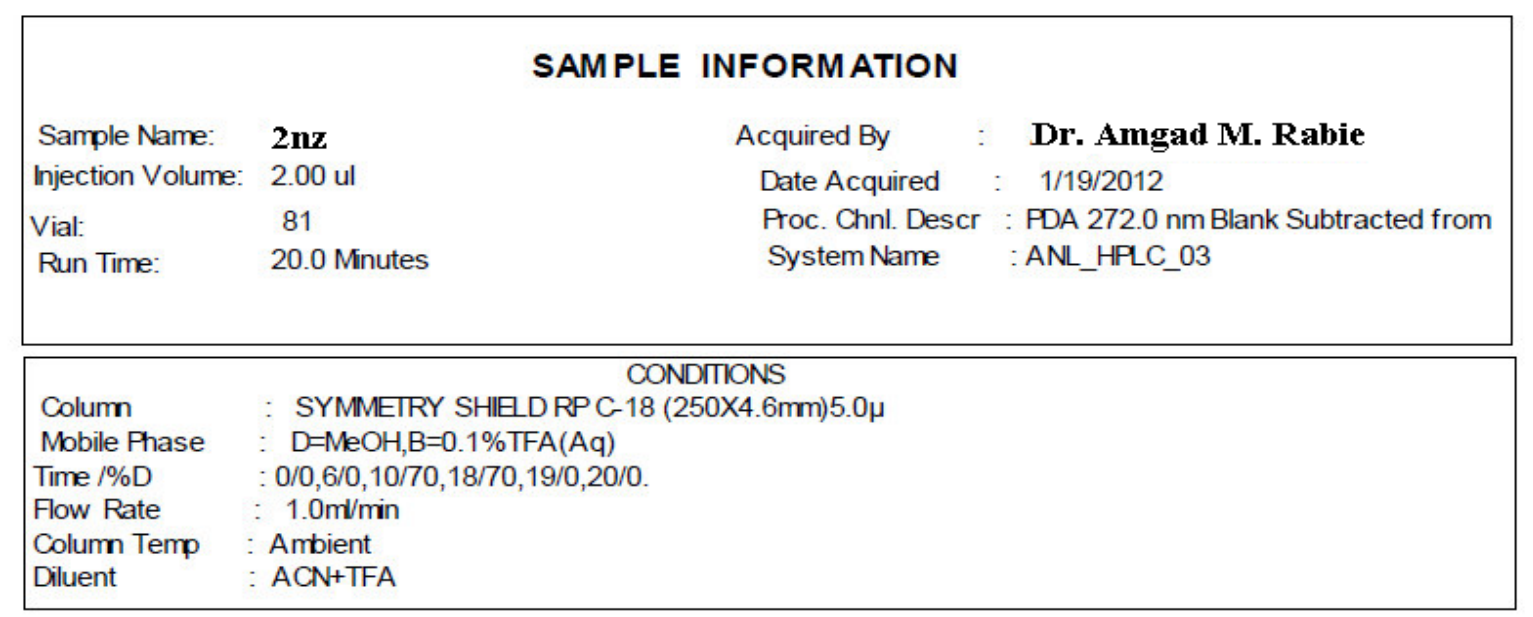

Purity chromatogram

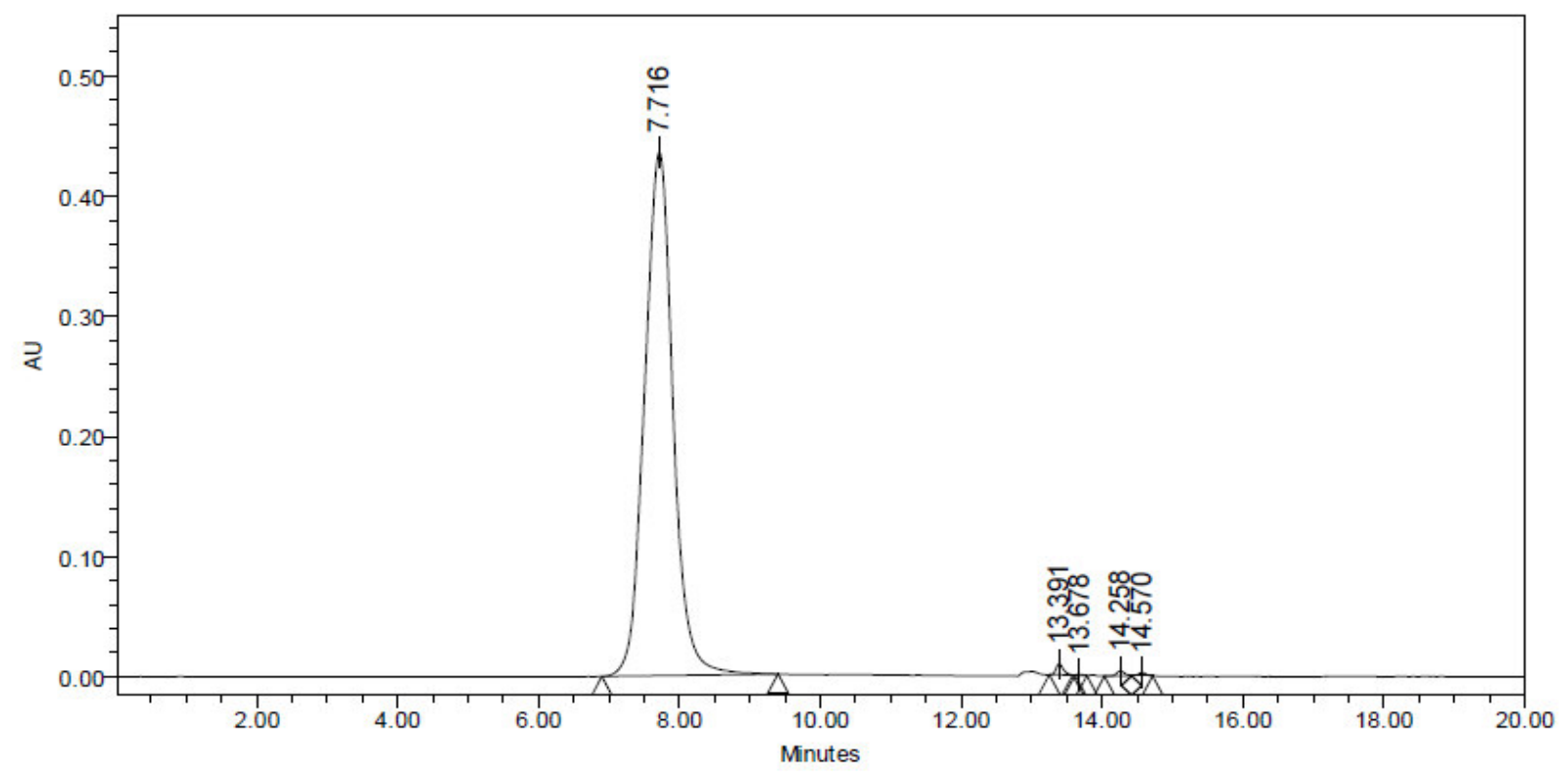

Peak Results

\begin{tabular}{|r|r|r|r|}
\hline & $\begin{array}{c}\mathrm{R} \mathrm{T} \\
(\mathrm{min})\end{array}$ & $\begin{array}{c}\text { Area } \\
\left(\mu \mathrm{V}^{*} \mathrm{sec}\right)\end{array}$ & $\%$ Area \\
\hline 1 & 7.716 & 12252904 & 98.99 \\
\hline 2 & 13.391 & 66007 & 0.53 \\
\hline 3 & 13.678 & 4261 & 0.03 \\
\hline 4 & 14.258 & 34128 & 0.27 \\
\hline 5 & 14.570 & 21976 & 0.18 \\
\hline
\end{tabular}

- Aq = aqueous.

Figure 4. A scanned copy of the HPLC chart of analysis of compound $2 \mathrm{nz}$ obtained in this work (including sample information, analytical conditions, purity chromatogram, and peak results) 


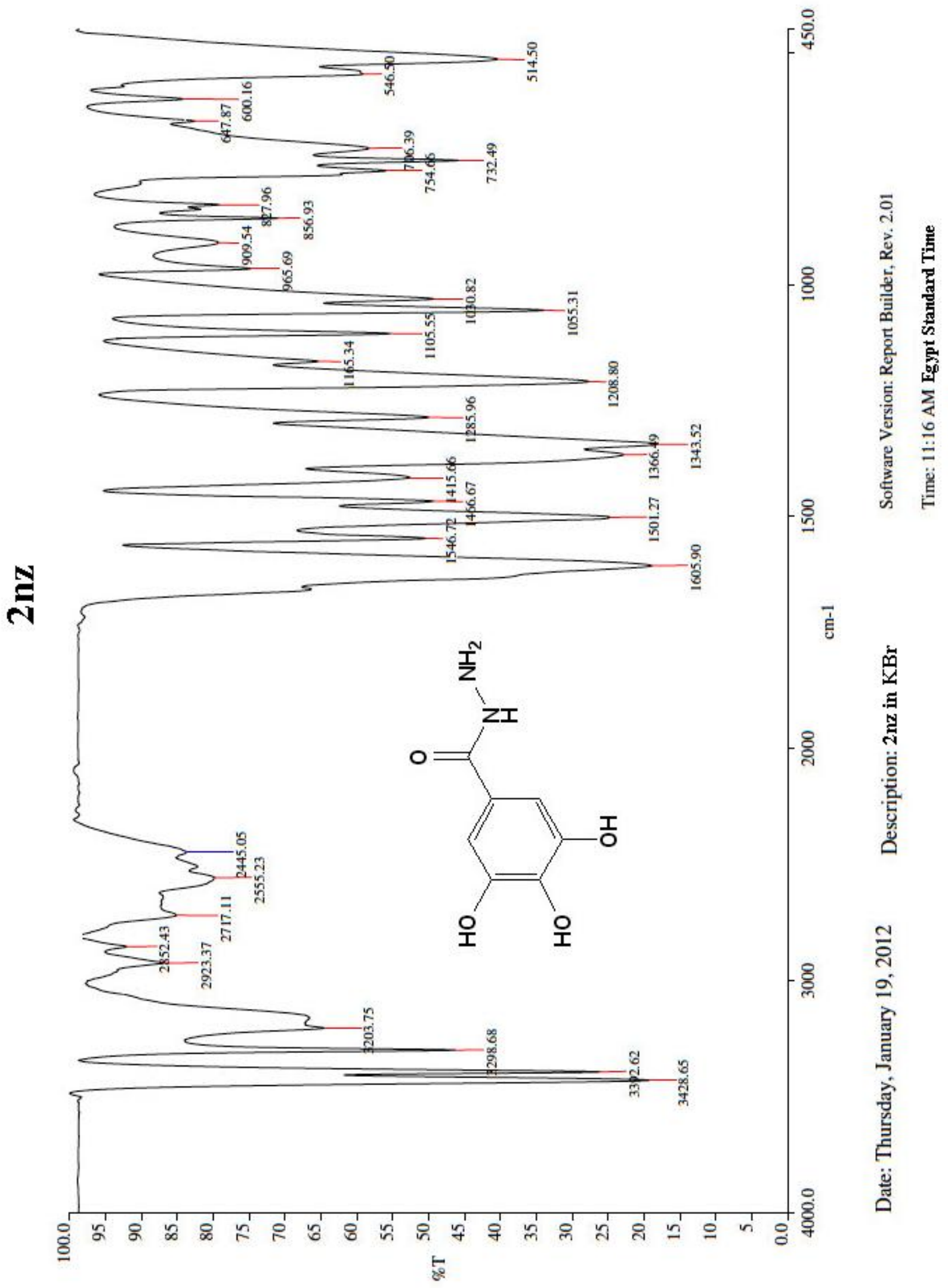

Figure 5. A scanned copy of the spectral chart obtained upon IR spectroscopical analysis of the sample of the compound $2 \mathbf{n z}$ 


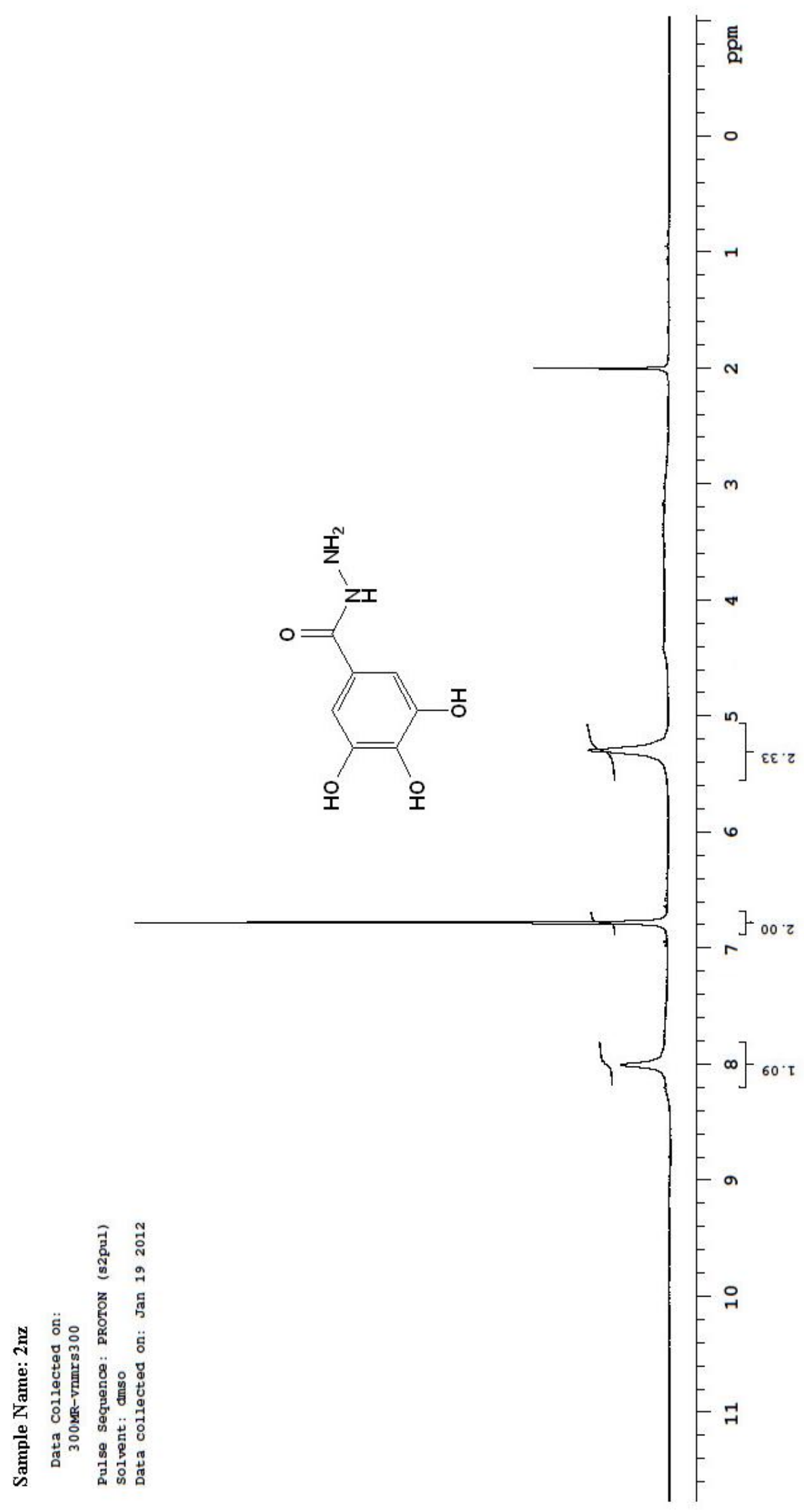

Figure 6. A scanned copy of the spectral chart obtained upon ${ }^{1} \mathrm{H}-\mathrm{NMR}$ spectroscopical analysis of the sample of the compound $\mathbf{2 n z}$ 


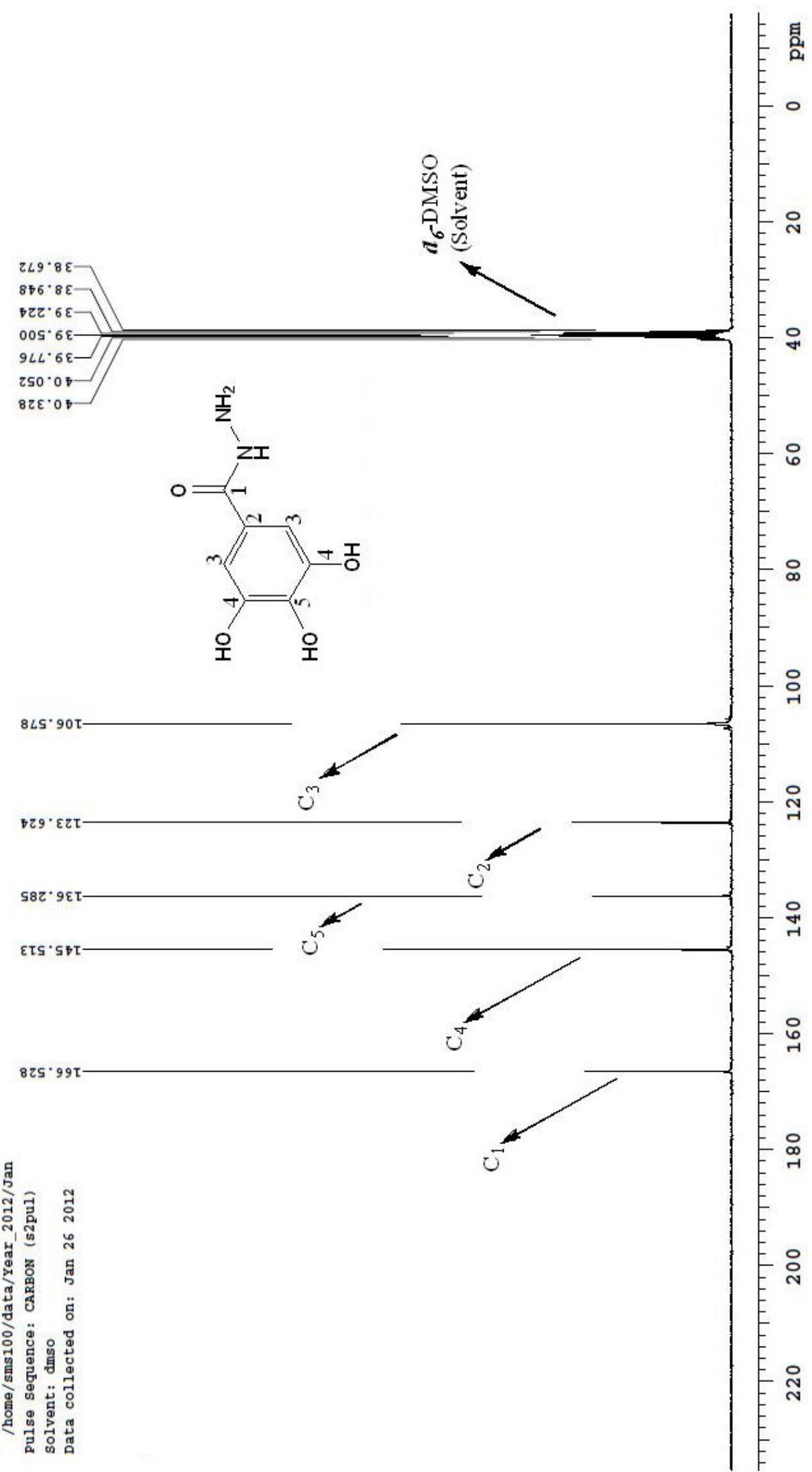

Figure 7. A scanned copy of the spectral chart (explained) obtained upon ${ }^{13} \mathrm{C}-\mathrm{NMR}$ spectroscopical analysis of the sample of the compound $\mathbf{2 n z}$ 


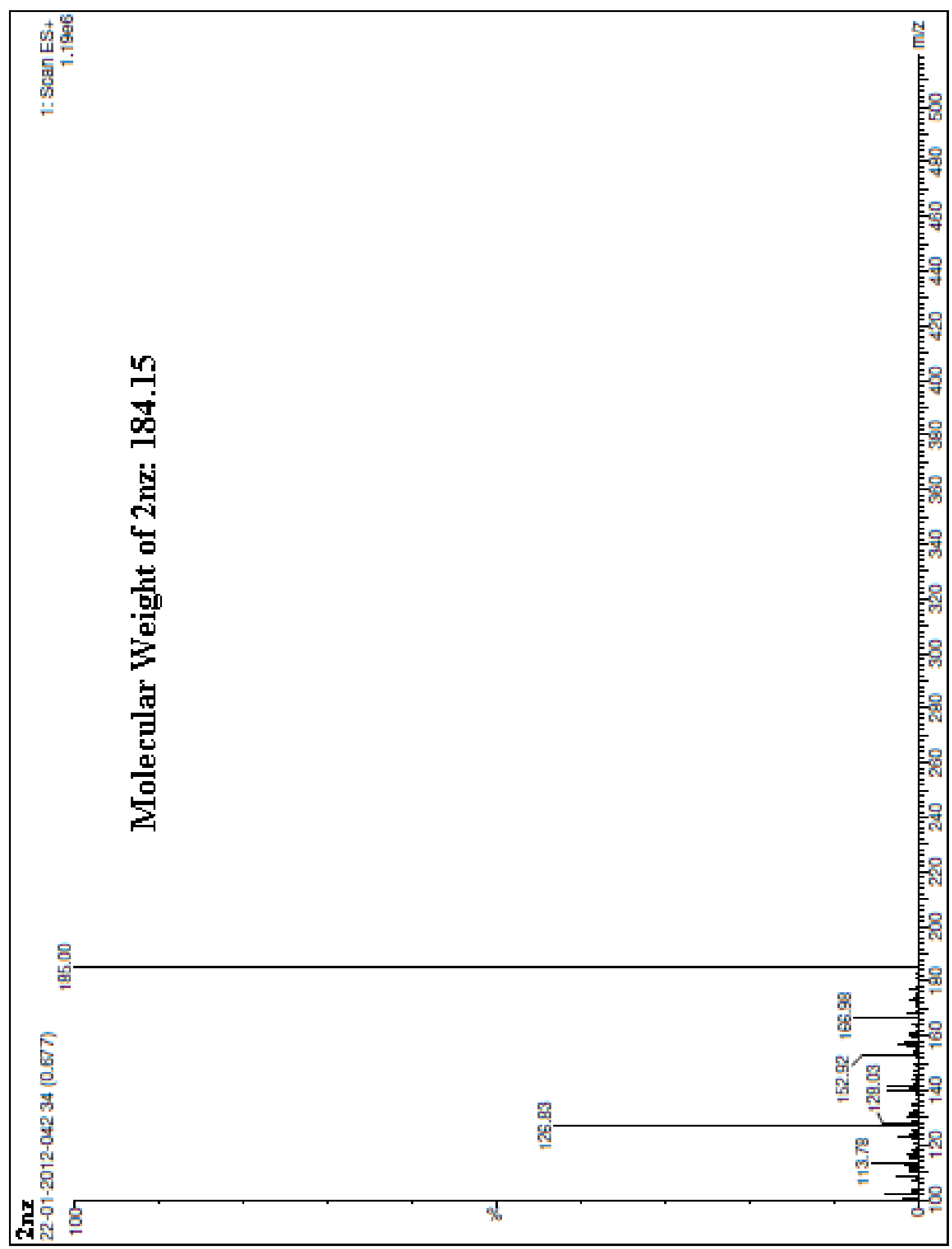

Figure 8. A scanned copy of the spectral chart obtained upon MS analysis of the sample of the compound $\mathbf{2 n z}$ 
Amgad M. Rabie et al: : Design, Synthesis, and Biological Evaluation of Novel 5-Substituted-2-(3,4,5-trihydroxyphenyl)-1,3,4-oxadiazoles as Potent Antioxidants

Table 3. Reaction details (by both methods A and B) for the synthesis of compounds $\mathbf{3 n - z}$

\begin{tabular}{|c|c|c|c|c|}
\hline \multirow[b]{2}{*}{$\begin{array}{l}\text { Compound } \\
\text { Code }\end{array}$} & \multirow{2}{*}{$\begin{array}{c}\text { S.C.A. }(\mathrm{R}-\mathrm{COOH})^{\mathrm{a}} \\
(\text { Entry })\end{array}$} & \multirow[b]{2}{*}{$\begin{array}{l}\text { Molar Ratio } \\
\text { of S.C.A.:2nz }\end{array}$} & \multicolumn{2}{|c|}{ Reaction Time \& Heating Power } \\
\hline & & & $\begin{array}{l}\text { Conv. (h), } \\
\text { Temperature }\end{array}$ & $\begin{array}{c}\text { MW (min), } \\
\text { Power Level (W) }\end{array}$ \\
\hline $3 \mathbf{n}$ & $\begin{array}{c}\mathrm{CH}_{3}-\left(\mathrm{CH}_{2}\right)_{14}-\mathrm{COOH} \\
\text { Palmitic Acid }\end{array}$ & $1: 1$ & 4, under reflux & 4,800 \\
\hline 30 & & $1: 1$ & 3 , under reflux & 4,800 \\
\hline $3 p$ & tic Acid & $1: 1$ & 3 , under reflux & 4,300 \\
\hline $3 q$ & & $1: 1$ & 3 , under reflux & 4,300 \\
\hline $3 \mathbf{r}$ & & $1: 1$ & 9 , under reflux & 6,800 \\
\hline $3 \mathrm{~s}$ & & $1: 2$ & 8 , under reflux & 8,600 \\
\hline $3 t$ & & $1: 2$ & 3 , under reflux & 4,600 \\
\hline $3 \mathbf{u}$ & & $1: 3$ & 4, under reflux & 5,600 \\
\hline $3 v$ & & $1: 1$ & 5 , under reflux & 5,800 \\
\hline $3 w$ & & $1: 2$ & 3 , under reflux & 4,450 \\
\hline $3 \mathbf{x}$ & & $1: 1$ & 5 , under reflux & 7,600 \\
\hline $3 \mathbf{y}$ & & $1: 1$ & 6 , under reflux & 9,600 \\
\hline $3 z$ & & $1: 1$ & 7 , under reflux & 10,800 \\
\hline
\end{tabular}

${ }^{\mathrm{a}}$ The R substituents in di- and tricarboxylic acids are modified in the produced 1,3,4-oxadiazole compounds (3n-z) as previously shown in Table 1 . 
Table 4. Comparative assessment of Conv. method versus MW method of synthesis of 1,3,4-oxadiazole compounds (3n-z) from their precursors in terms of overall yield percentage, heating (reaction) time, and energy consumption, with their improvement percentages or times in the MW method relative to the Conv. one

\begin{tabular}{|c|c|c|c|}
\hline Item & Conv. Method & MW Method & Improvement \\
\hline Overall Yield (Range) & $73.0-94.0 \%$ & $95.0-99.2 \%$ & $5.2-24.5 \%$ increase (more productive method) \\
\hline Heating Time (Range) & $3-9 \mathrm{~h}$ & $4-10 \mathrm{~min}$ & $40-90$ times less (time-saving method) \\
\hline Energy Consumption Range $(\mathbf{K W h})$ & $6-18$ & $0.02-0.13^{\mathrm{a}}$ & About $105-300$ times less (energy-saving method) \\
\hline
\end{tabular}

${ }^{\mathrm{a}} \mathrm{P}$ range of MW oven for the synthesis of $\mathbf{3 n - z}$, in this present work, is $300-800 \mathrm{~W}$.

Undoubted elucidation and confirmation of the chemical structures of the newly synthesized compounds $\mathbf{3 n}-\mathbf{z}$ were accomplished using both the spectroscopical (IR, ${ }^{1} \mathrm{H}-\mathrm{NMR}$, and MS) [52] and elemental (i.e., micro) analyses. In IR spectra, the absence of the common strong sharp characteristic absorption peak of amide $\mathrm{C}=\mathrm{O}$ (of the hydrazide 2nz) stretching which previously appeared at a frequency of $1606 \mathrm{~cm}^{-1}$ was an excellent indication of conversion of the hydrazide $\mathbf{2 n z}$ (with each of the carboxylic acids) to the 1,3,4-oxadiazole heteroring (along with the presence of the characteristic IR peaks of the N-N, $\mathrm{C}-\mathrm{N}$, and $\mathrm{C}-\mathrm{O}$ moieties, which are the moieties that constitute the 1,3,4-oxadiazole ring, also confirmed the formation of the 1,3,4-oxadiazole ring), in addition, the presence of the common strong and broad characteristic absorption peaks of $\mathrm{OH}$ stretching at frequencies of $3476-3372 \mathrm{~cm}^{-1}$ was a good indication of the existence of the three phenolic hydroxyl groups attached to a benzene ring (its existence and attachment to position 2 of the formed 1,3,4-oxadiazole ring was confirmed by the presence of the common characteristic absorption peaks of the aromatic $\mathrm{C}=\mathrm{C}$ and $=\mathrm{C}-\mathrm{H}$ moieties in all the produced compounds of this 1,3,4-oxadiazole series), and, finally, the other varied absorption peaks representing the specific different $\mathrm{R}$ groups that are attached to position 5 of the 1,3,4-oxadiazole ring in each compound in this series ( $\mathbf{3 n - z}$ ) were specific confirmations for the chemical structure of each compound [52]. In ${ }^{1} \mathrm{H}-\mathrm{NMR}$ spectra, mainly, the clear absence of any characteristic signal for the proton of the $\mathrm{OH}$ group of any carboxyl moiety in the range of 10.5-15.0 ppm (as all the ${ }^{1} \mathrm{H}-\mathrm{NMR}$ spectral charts resulted from the analysis of compounds $\mathbf{3 n - z}$ contain no signals in this large region of the spectrum at all) was an excellent confirmation of conversion of all the carboxylic acids (through reacting with 2nz) to the substituted 1,3,4-oxadiazole heteroring, furthermore, the general presence of the characteristic singlet signals at 5.333-5.548 ppm indicated the existence of the three protons of the three adjacent phenolic hydroxyl groups attached to a benzene ring (its existence and attachment to position 2 of the formed 1,3,4-oxadiazole ring was confirmed by the presence of the common characteristic singlet signals of the only two protons of this phenyl ring at 6.716-7.313 ppm in all the produced compounds of this 1,3,4-oxadiazole series), and, finally, the other varied signals representing the protons (if present) of specific different $\mathrm{R}$ groups that are attached to position 5 of the 1,3,4-oxadiazole ring in each compound in this series (3n-z) were specific confirmations for the chemical structure of most compounds among compounds $\mathbf{3 n - z}$ (only those whose $\mathrm{R}$ group has protons in its structure) [52]. The specific values of MS and elemental analyses (see the Experimental Work for details) gave confirmatory assignments and further final evidences for the characterization of the structures of all these newly synthesized compounds (3n-z) [52].

\subsection{Biological Evaluation}

The in vitro antioxidant assays used in this present work for the antiradical pharmacological evaluation of the target 1,3,4-oxadiazole derivatives $\mathbf{3 n}-\mathbf{z}$ are the following ABTS test (2,2'-azinobis(3-ethylbenzothiazoline-6-sulfonic acid) radical cation decolorization assay) and DPPH test (2,2-diphenyl-1-picrylhydrazyl free radical bleaching assay) which are two of the most common and famous assays used as a base for the further biological evaluation of the antioxidant activities of new organic compounds.

\subsubsection{ABTS Test}

ABTS test results (antioxidant $\mathrm{IC}_{50}$ values for the target compounds $3 \mathbf{n}-\mathbf{z}$ ) are summarized in Table 5 below. A comprehensive overview of the results in Table 5 reveals that the target compounds $\mathbf{3 n - z}$ displayed various degrees of free radical scavenging activity towards the ABTS radical, with decreasing activity in the following order: $\mathbf{3 w}>\mathbf{3 s}>$ $3 p>3 t>3 o>3 r>3 v>3 z>3 q>3 x>3 u>3 y>3 n$. The most potent compounds are the two compounds $\mathbf{3 w}$ and $\mathbf{3 s}$ with in vitro antiradical effects $\left(\mathrm{IC}_{50}=24.40\right.$ and $24.67 \mu \mathrm{M}$, respectively) higher than that of L-ascorbic acid $\left(\mathrm{IC}_{50}=\right.$ $30.08 \mu \mathrm{M}$ ), while other compounds demonstrated either close and comparable activity to that of L-ascorbic acid (such as compounds $\mathbf{3 p}$ and $\mathbf{3 t}$ which have $\mathrm{IC}_{50}=30.70$ and $31.11 \mu \mathrm{M}$, respectively), or lower and weaker activity than that of L-ascorbic acid (such as compounds $\mathbf{3 q}, \mathbf{3 x}, \mathbf{3 u}, \mathbf{3 y}$, and $3 \mathbf{n}$ which have $\mathrm{IC}_{50}=105.26,116.16,124.89,132.37$, and $177.93 \mu \mathrm{M}$, respectively).

Compounds $\mathbf{3 w}$ and $\mathbf{3 s}$ are the most effective anti-ABTS ${ }^{+}$1,3,4-oxadiazoles among all the thirteen derivatives due to the presence of relatively higher but balanced number of $\mathrm{OH}$ groups in their structures (in addition to the presence of complete strong conjugation and resonance in case of compound $\mathbf{3 w}$ ), which strongly increases the in vitro antioxidant capacities of these two new compounds (as a result of the extensive hydrogen bonds formation and the higher aqueous solubility). On the 
other hand, compound $\mathbf{3 n}$ has relatively the lowest in vitro antioxidant activity among the thirteen 1,3,4-oxadiazole compounds possibly because its $\mathrm{R}$ group is a very long straight aliphatic lipophilic chain as it consists of fifteen $\mathrm{C}$ atoms (i.e., not a small aliphatic structure) and this extremely inhibits the electron-donating effect of $\mathrm{R}$ group on the oxadiazole ring (in vitro not in vivo) which, in turn, drastically decreases the free radical scavenging activity of the compound.

Table 5. Results of the antioxidant capacities (expressed as $\mathrm{IC}_{50}$ values) of the target 1,3,4-oxadiazole compounds (3n-z) in the ABTS test (using L-ascorbic acid as a reference antioxidant)

\begin{tabular}{|c|c|}
\hline Compound & $\mathbf{I C}_{\mathbf{5 0}}(\boldsymbol{\mu M})^{\mathbf{a}}$ \\
\hline $\mathbf{3 n}$ & $177.93 \pm 0.83$ \\
\hline $\mathbf{3 o}$ & $38.35 \pm 0.28$ \\
\hline $\mathbf{3 p}$ & $30.70 \pm 0.22$ \\
\hline $\mathbf{3 q}$ & $105.26 \pm 0.69$ \\
\hline $\mathbf{3 r}$ & $40.22 \pm 0.28$ \\
\hline $\mathbf{3 s}$ & $24.67 \pm 0.17^{\mathrm{b}}$ \\
\hline $\mathbf{3 t}$ & $31.11 \pm 0.23$ \\
\hline $\mathbf{3 u}$ & $124.89 \pm 0.73$ \\
\hline $\mathbf{3 v}$ & $42.70 \pm 0.30$ \\
\hline $\mathbf{3 w}$ & $24.40 \pm 0.17^{\mathrm{b}}$ \\
\hline $\mathbf{3 x}$ & $116.16 \pm 0.71$ \\
\hline $\mathbf{3 y}$ & $132.37 \pm 0.74$ \\
\hline $\mathbf{3 z}$ & $43.24 \pm 0.31$ \\
\hline L-Ascorbic acid (Reference) & $30.08 \pm 0.22$ \\
\hline
\end{tabular}

${ }^{\mathrm{a}} \mathrm{IC}_{50}$ values are means of three independent determinations (measurements), so results are expressed as the mean (the average value) $\pm \mathrm{SD}$ (the standard deviation) of triplicate analysis obtained from GraphPad Prism 6 software (U.S.A., 2015).

${ }^{\mathrm{b}}$ Test compounds with the least $\mathrm{IC}_{50}$ values (i.e., with $\mathrm{IC}_{50}$ values less than that of L-ascorbic acid) are the most active antioxidant compounds in this assay.

\subsubsection{DPPH Test}

DPPH test results (antioxidant $\mathrm{IC}_{50}$ values for the target compounds 3n-z) are summarized in Table 6. A complete overview of the results in Table 6 reveals that, exactly as with the ABTS radical, the target compounds 3n-z displayed various degrees of free radical scavenging activity towards the DPPH radical, with decreasing activity in the following order: $3 \mathbf{w}>\mathbf{3 s}>\mathbf{3 u}>\mathbf{3 p}>\mathbf{3 t}>\mathbf{3 o}>\mathbf{3 r}>$ $\mathbf{3 v}>\mathbf{3 z}>\mathbf{3 q}>\mathbf{3 x}>\mathbf{3 y}>\mathbf{3 n}$. The most potent compounds are the three compounds $\mathbf{3 w}, \mathbf{3 s}$, and $\mathbf{3 u}$ with in vitro antiradical effects $\left(\mathrm{IC}_{50}=14.61,14.77\right.$, and $16.02 \mu \mathrm{M}$, respectively) higher than that of both $\mathrm{L}$-ascorbic acid and trolox $\left(\mathrm{IC}_{50}=18.02\right.$ and $30.60 \mu \mathrm{M}$, respectively), while other compounds demonstrated either close and comparable activity to that of L-ascorbic acid with higher activity than that of trolox (such as compounds $\mathbf{3 p}$ and $\mathbf{3 t}$ which have $\mathrm{IC}_{50}=18.38$ and $18.63 \mu \mathrm{M}$, respectively), or lower and weaker activity than that of both L-ascorbic acid and trolox (only compounds $\mathbf{3 q}, \mathbf{3 x}, \mathbf{3 y}$, and $\mathbf{3 n}$ which have $\mathrm{IC}_{50}=$
$63.05,69.57,79.28$, and $106.58 \mu \mathrm{M}$, respectively). It was generally noted that most of the compounds $3 \mathbf{n}-\mathbf{z}$ have stronger antioxidant activities than the potent antioxidant trolox.

These results prove that compounds $\mathbf{3 n - z}$ are obviously good-excellent antioxidants (i.e., effective anti-DPPH compounds). Being very close and relatively similar, the differences in values in this assay can be explained by and attributed to the same effects of structural modifications (i.e., differences) that were previously mentioned under ABTS test. The results of this DPPH assay are very closely related to those of ABTS assay (with the only exception, compound $\mathbf{3 u}$, which has an excellent antiradical activity against $\mathrm{DPPH}$ free radical, as its $\mathrm{IC}_{50}$ value equals about $16 \mu \mathrm{M}$, unlike its weak efficiency against the $\mathrm{ABTS}^{+}$radical cation) indicating that these new 1,3,4-oxadiazole derivatives behave with the same relative manner and efficiency against both radicals (DPPH and $\mathrm{ABTS}^{+}$), i.e., these new 1,3,4-oxadiazole derivatives react with and scavenge both types of radicals in closely efficient ways and this makes them having a wide spectrum of antioxidant activities against the different types of free radicals. An important observation is that the $\mathrm{IC}_{50}$ values of all the compounds 3n-z in DPPH assay are smaller than the corresponding ones of the same compounds in ABTS assay suggesting that these compounds are more potent scavengers of free radicals of the DPPH type than those of the $\mathrm{ABTS}^{+}$type.

Table 6. Results of the antioxidant capacities (expressed as $\mathrm{IC}_{50}$ values) of the target 1,3,4-oxadiazole compounds (3n-z) in the DPPH test (using $\mathrm{L}$-ascorbic acid and trolox as antioxidant references)

\begin{tabular}{|c|c|}
\hline Compound & IC $_{\mathbf{5 0}}(\boldsymbol{\mu} \mathbf{M})^{\mathbf{a}}$ \\
\hline 3n & $106.58 \pm 0.67$ \\
\hline 3o & $22.97 \pm 0.22$ \\
\hline $\mathbf{3 p}$ & $18.38 \pm 0.18$ \\
\hline $\mathbf{3 q}$ & $63.05 \pm 0.56$ \\
\hline $\mathbf{3 r}$ & $24.09 \pm 0.22$ \\
\hline $\mathbf{3 s}$ & $14.77 \pm 0.13^{\mathrm{b}}$ \\
\hline $\mathbf{3 t}$ & $18.63 \pm 0.19$ \\
\hline $\mathbf{3 u}$ & $16.02 \pm 0.16^{\mathrm{b}}$ \\
\hline $\mathbf{3 v}$ & $25.57 \pm 0.24$ \\
\hline $\mathbf{3 w}$ & $14.61 \pm 0.13^{\mathrm{b}}$ \\
\hline $\mathbf{3 x}$ & $69.57 \pm 0.58$ \\
\hline $\mathbf{3 y}$ & $79.28 \pm 0.60$ \\
\hline $\mathbf{3 z}$ & $25.90 \pm 0.25$ \\
\hline Trolox $(\mathbf{R e f e r e n c e ~ 2 )}$ & $18.02 \pm 0.18$ \\
\hline & $30.60 \pm 0.40$ \\
\hline L-Ascorbic acid (Reference 1) & \\
\hline
\end{tabular}

${ }^{\mathrm{a}} \mathrm{IC}_{50}$ values are means of three independent determinations, so results are expressed as the mean \pm SD of triplicate analysis obtained from GraphPad Prism 6 software (U.S.A., 2015).

${ }^{\mathrm{b}}$ Test compounds with the least $\mathrm{IC}_{50}$ values (i.e., with $\mathrm{IC}_{50}$ values less than those of both L-ascorbic acid and trolox) are the most active antioxidant compounds in this assay. 


\subsection{SAR (structure-antioxidant activity relationship)}

On correlating the modifications of the chemical structure (substituent $\mathrm{R}$ change) of the new compounds of the 5-substituted-2-(3,4,5-trihydroxyphenyl)-1,3,4-oxadiazoles (i.e., along the new series of compounds $\mathbf{3 n - z}$ ) with their in vitro antioxidant biological activity (in both ABTS and DPPH assays), it has been observed that:

- Simple short-chain aliphatic-R 5-substituted-2-(3,4, 5-trihydroxyphenyl)-1,3,4-oxadiazole compounds are generally more active as antioxidants than large complicated aromatic-R ones (supposing that there are not any additional moieties that affect the overall antioxidant activity).

- As the length of the aliphatic straight chain (if present) at position 5 of the 1,3,4-oxadiazole compounds increases, the antioxidant activity of these compounds gradually decreases until it reaches certain limit (e.g., fifteen carbon atoms or more) above which, the compounds become much less active than those have short aliphatic straight chains (one to three carbon atoms) and also than aromatic-R compounds (i.e., their antioxidant activities are relatively very weak), on a condition that there are not any additional moieties on the aliphatic chain that impart and add any antioxidant activity.

- Aromatic-R 5-substituted-2-(3,4,5-trihydroxyphenyl)-1, 3,4-oxadiazoles having complete resonating system (uninterrupted resonance effect) are generally more active as antioxidants than those having incomplete interrupted one.

- As the number of halogens (e.g., $\mathrm{Cl}$ and $\mathrm{Br}$ substituents) attached to the aliphatic side chain which is present at position 5 of the bioactive oxadiazole ring scaffold in aliphatic-R 5-substituted-2-(3,4,5-trihydroxyphenyl)-1, 3,4-oxadiazole compounds increases, the antioxidant activity of these compounds decreases in a relative way.

- Compounds that have considerable number of 1,3 , 4-oxadiazole rings and 3,4,5-trihydroxyphenyl groups are generally expected to be very potent antioxidant compounds and to have much more antioxidant activities than those have only one 1,3,4-oxadiazole ring and one 3,4,5-trihydroxyphenyl group.

- 5-Substituted-2-(3,4,5-trihydroxyphenyl)-1,3,4-oxadiazoles that have balanced lipophilic/hydrophilic properties are much more active in vitro as antioxidants than extremely lipophilic ones.

\section{Conclusions}

On the basis of "the combination principles", we have designed and synthesized, in very good to excellent yields, a novel series of 5-substituted-2-(3,4,5-trihydroxyphenyl)-1, 3,4-oxadiazole compounds (compounds 3n-z) in which a bioactive aromatic 1,3,4-oxadiazole ring is directly linked with an antioxidant 3,4,5-trihydroxyphenyl moiety and an aiding substituent at the two carbons of the ring, the produced 2,5-disubstituted-1,3,4-oxadiazoles were characterized by most different spectral and elemental analytical methods. The synthesized compounds showed a wide range of potentially promising antioxidant activities. Depending on their pharmacological scavenging effects against the tested radicals in vitro, these target compounds can be categorized relative to L-ascorbic acid and trolox into three distinguished classes of antioxidants, as they can be classified into either very potent and excellent antioxidants (group I, compounds $\mathbf{3 s}, \mathbf{u}, \mathbf{w}$ ), moderately potent and good antioxidants (group II, compounds 3o,p,r,t,v,z), or relatively less potent and mild antioxidants (group III, compounds 3n,q,x,y). Compounds 3s, $\mathbf{u}, \mathbf{w}$ exhibited interestingly very potent antioxidant activity and they could be very promising lead and parent compounds for the design and synthesis of new antioxidant compounds and medicines by further in vivo biological evaluation, structural modifications, deep investigations, and advanced clinical studies.

\section{Experimental Work}

\subsection{Chemical Synthesis}

\subsubsection{General Data}

All reactions were performed with commercially available reagents. All chemicals (reagents and solvents) were of analytical grade, purchased from commercial suppliers, and were used as received without further purification (if needed, some solvents were dried by standard methods). Acidic alumina (aluminum oxide; acidic; Brockmann I; 150 mesh; 58 А CAMAG 506-C-I; surface area $=155 \mathrm{~m}^{2} / \mathrm{g} ; \mathrm{pH}=6$ ) was used as an efficient adsorbent for the MW reactions of the last step. MWI (microwave irradiation) for $\mathrm{MW}$ reactions was carried out in an unmodified domestic MW oven (Samsung type, model M1733N with T.D.S. (Triple Distribution System) property, and having a power level of $100-800 \mathrm{~W}$ ) operated at 2.45 $\mathrm{GHz}$. TLC was used to monitor the progress of all the reactions to reach their completion (reaction times) and to check the purity of the compounds synthesized, it was carried out on TLC silica gel $60 \mathrm{~F}_{254}$ plates (plates of aluminum sheets precoated with unmodified silica gel 60 $\mathrm{F}_{254}$ to a layer thickness of $0.20 \mathrm{~mm}$, purchased from E. Merck, Merck Millipore Division or Merck Chemicals, Merck KGaA, Darmstadt, Germany) as the stationary phase using petroleum ether/ethyl acetate/absolute EtOH (6:3:2, $\mathrm{v} / \mathrm{v} / \mathrm{v}$ "v = volume") mixture (for all the reactions except for monitoring the hydrazinolysis reaction for the synthesis of compound $2 \mathrm{nz}$ in this work as a mixture of $5 \%$ absolute $\mathrm{MeOH}$ in $\mathrm{CH}_{2} \mathrm{Cl}_{2}$ was used as the mobile phase for it) as the eluting solvent system and the chromatograms spots were visualized and observed under the used UV (ultraviolet) light at wavelengths of 254 (mainly) and $366 \mathrm{~nm}$ to detect the produced components. The $\mathrm{pH}$ of reaction mixtures 
solutions was measured (to be adjusted) by a portable waterproof $\mathrm{pH} / \mathrm{ORP}$ meter with smart electrodes and log-on-demand (HI 98150, HANNA instruments, Hungary Kft., Hungary) and this was done mainly to get the neutral $\mathrm{pH}$ (about 8) in the neutralization step for each reaction mixture solution contained $\mathrm{POCl}_{3}$ as excess with the product. Evaporation and concentration was carried out by using rotavap (rotary evaporator) under reduced pressure (for the efficient and gentle removal of solvents from reaction mixtures). A lyophilizer (freeze dryer, model FD8-8T, SIM international, U.S.A.) was used for lyophilizing purpose. Melting points $\left({ }^{\circ} \mathrm{C}\right)$ of all the synthesized compounds were measured and recorded in open glass capillaries using Fisher-Johns melting point apparatus and were uncorrected. IR spectra were recorded on Nicolet $^{\mathrm{TM}}$ iS ${ }^{\mathrm{TM}} 10$ Mid-Infrared (ThermoFisher Scientific) FT-IR spectrometer ( $v$ in $\mathrm{cm}^{-1}$ ) using $\mathrm{KBr}$ (potassium bromide) disks at the Central Laboratory (Faculty of Pharmacy, Mansoura University, Mansoura, Egypt) (Abbreviations in IR characterization data: Str. = Strong (if not mentioned, this means that the peak is weak to medium in intensity); Bro. = Broad (if not mentioned, this means that the peak is sharp, not broad enough, or overlapped with other peaks); Aliph. = Aliphatic; Arom. = Aromatic). ${ }^{1} \mathrm{H}-\mathrm{NMR}$ spectra were recorded on Varian Gemini-300 spectrometer (Mercury-300BB "NMR300") at about $300 \mathrm{MHz}$ using TMS (tetramethylsilane) as an internal standard at the Microanalytical Center (Faculty of Science, Cairo University, Cairo, Egypt) and their chemical shifts values $(\delta)$ were given in ppm downfield from TMS at a temperature of $30{ }^{\circ} \mathrm{C}$ using either $\mathrm{CDCl}_{3}$ (deuterated chloroform) or DMSO- $d_{6}$ (deuterated dimethylsulfoxide) as a solvent (according to the solubility of each analyzed compound) (Abbreviations in ${ }^{1} H-N M R$ characterization data: $\mathrm{s}=$ singlet; $\mathrm{d}=$ doublet; $\mathrm{t}=$ triplet; $\mathrm{q}=$ quartet; $\mathrm{m}=$ multiplet; $\mathrm{dd}=$ double doublet (a doublet of doublets); $J=$ Coupling Constant (expressed in $\mathrm{Hz}$ ); Aliph. = Aliphatic; Arom. = Aromatic; $o=$ ortho; $m=$ meta; $p=$ para). ${ }^{13} \mathrm{C}-\mathrm{NMR}$ spectrum for only compound $\mathbf{2 n z}$ was recorded also on Varian Gemini-300 spectrometer (Mercury-300BB "NMR300") at about $75 \mathrm{MHz}$ using TMS as an internal standard at the Microanalytical Center (Faculty of Science, Cairo University, Cairo, Egypt) and its chemical shifts values $(\delta)$ were given in ppm downfield from TMS at a temperature of $30{ }^{\circ} \mathrm{C}$ using DMSO- $d_{6}$ as a solvent (Abbreviation in ${ }^{13} C$-NMR characterization data: Arom. = Aromatic). MS analyses were performed on Shimadzu Qp-2010 Plus at $70 \mathrm{eV}$ and results were represented by $\mathrm{m} / \mathrm{z}$ (Rel. Int.), i.e., mass/charge (relative intensity), at the Microanalytical Center (Faculty of Science, Cairo University, Cairo, Egypt). Elemental analyses were performed at the Microanalytical Center (Faculty of Science, Cairo University, Cairo, Egypt) in order to determine C, H, and $\mathrm{N}$ contents of all the newly synthesized compounds and the previously synthesized compound $\mathbf{2 n z}$ (they, all, were in full agreement with the calculated theoretical values). Other abbreviations in synthetic procedures and characterization data below: abs. = absolute; R.T. = room temperature; EtOAc = ethyl acetate; M.P. = Melting point; Recryst. = Recrystallized; DEE = diethyl ether; v/v = volume per volume; Col. \& App. = Color \& Appearance; M.Wt. = Molecular Weight; Elem. Anal. = Elemental Analyses; DMF = dimethylformamide; dec. $=$ with decomposition .

\subsubsection{Conventional Synthesis of Ethyl 3,4,5-Trihydroxybenzoate (1nz)}

To a stirred solution of anhydrous gallic acid ( 0.1 mole, $17.012 \mathrm{~g})$ in abs. EtOH $(500 \mathrm{~mL})$ in a round-bottomed flask, Conc. $\mathrm{H}_{2} \mathrm{SO}_{4}(5 \mathrm{~mL})$ was added. The resulted reaction mixture was refluxed with stirring at $90-100{ }^{\circ} \mathrm{C}$ for $15 \mathrm{~h}$. After reaction completion (i.e., no more $\mathrm{H}_{2} \mathrm{O}$ was being distilled off), the reaction mixture was cooled to R.T., then excess EtOH was completely evaporated (distilled off) on a water bath, and the reaction mixture was allowed to cool to R.T. again. The residue remained was taken up in pure distilled $\mathrm{H}_{2} \mathrm{O}$ in a separatory funnel and the flask was rinsed with a few $\mathrm{mL}$ of pure distilled $\mathrm{H}_{2} \mathrm{O}$ which were also poured into the separatory funnel. The formed aqueous solution was extracted by shaking it vigorously with EtOAc for three times $(3 \times 250 \mathrm{~mL}$; the upper organic layer was carefully taken each time while the lower aqueous layer was finally rejected), the combined organic layers (extracts) were returned to a pure dry separatory funnel to be subsequently shaken with a strong solution of $\mathrm{NaHCO}_{3}$ (sodium bicarbonate) until all the free gallic acid was removed (i.e., until no more effervescence), then they were washed with distilled $\mathrm{H}_{2} \mathrm{O}$ and brine (a highly concentrated $\mathrm{NaCl}$ (sodium chloride) solution in $\mathrm{H}_{2} \mathrm{O}$ ). The organic layer was taken and dried over anhydrous $\mathrm{Na}_{2} \mathrm{SO}_{4}$ (sodium sulfate) during filtration (directly into the pure dry round-bottomed flask of the rotavap), then the filtrate was concentrated by evaporation in rotavap under reduced pressure, left in air to be completely dry to give a crude white solid mass of the product 1nz which upon further purification by recrystallization from hexane, it gives the pure product $1 \mathrm{nz}$ (16.508 g, yield $\approx 83.3 \%$ (as reported $[26,27])$ ) which is a white amorphous powder with M.P. = $148-150{ }^{\circ} \mathrm{C}$ (as reported [26,27]).

\subsubsection{Synthesis of 3,4,5-Trihydroxybenzohydrazide (2nz)}

2nz was synthesized by the following two methods:

a- Common Conventional Heating Method (from 1nz): A mixture of $1 \mathbf{n z}(0.1$ mole, $19.817 \mathrm{~g})$ and slight excess $\mathrm{NH}_{2} \mathrm{NH}_{2} . \mathrm{H}_{2} \mathrm{O}(0.11$ mole; about $5.35 \mathrm{~mL})$ was dissolved in abs. EtOH (about 300-350 mL, i.e., the least amount needed to make the reaction mixture a clear solution) in a round-bottomed flask, then the resulted reaction mixture was mixed gently and refluxed with stirring for $6 \mathrm{~h}$. The progress of the reaction was monitored on TLC plates. After reaction completion, the reaction mixture was cooled to R.T., then excess EtOH was completely distilled off on a water bath, and the reaction mixture was allowed to cool to R.T. again. The reaction mixture was poured onto ice-cold water with stirring and the white mass or precipitate 
obtained was filtered, washed with distilled $\mathrm{H}_{2} \mathrm{O}$ several times, and dried under vacuum (or left in air to be completely dry) to give a crude pale white solid mass of the product $2 \mathrm{nz}$ which was further purified by HPLC analysis ( $\mathbf{2 n z}$ was successfully obtained with very excellent purity of about 99\%; see details below) and recryst. twice from DEE and abs. $\mathrm{MeOH}(1: 1, \mathrm{v} / \mathrm{v})$ to give about $16.574 \mathrm{~g}$ (yield = $90.0 \%$ (as reported [37])) of the pure $\mathbf{2 n z}$ (pale white to buff fine powder) with M.P. $=294-296^{\circ} \mathrm{C}\left(\right.$ reported one $=290^{\circ} \mathrm{C}$ [48] $)$.

b- New Green Solvent-free One-pot MW-assisted Method (from gallic acid): A mixture of gallic acid (0.01 mole, $1.7012 \mathrm{~g})$ and slight excess $\mathrm{NH}_{2} \mathrm{NH}_{2} \cdot \mathrm{H}_{2} \mathrm{O}(0.012$ mole; about $0.584 \mathrm{~mL}$ ) was taken in a $150-\mathrm{mL}$ conical flask, the resulted paste of the reaction mixture was well mixed, then the flask was covered with aluminum foil and subjected to MWI intermittently at intervals of $30 \mathrm{~s}$ for 2 $\min$ (i.e., 4 intervals of $30 \mathrm{~s}$ ) at a power level of $800 \mathrm{~W}$. The progress of the reaction was monitored on TLC plates till it was over after the fourth interval. After reaction completion, the reaction mixture was cooled to $-20{ }^{\circ} \mathrm{C}$ and then it was lyophilized at $-50{ }^{\circ} \mathrm{C}$. The white product obtained was washed with distilled $\mathrm{H}_{2} \mathrm{O}$ several times and dried under vacuum (or left in air to be completely dry) to give a crude pale white solid mass of the product $\mathbf{2 n z}$ which was further purified by HPLC analysis (2nz was successfully obtained with very excellent purity of about $99 \%$; see details below) and recryst. twice from DEE and abs. $\mathrm{MeOH}(1: 1, \mathrm{v} / \mathrm{v})$ to give about $1.8084 \mathrm{~g}$ (yield $=98.2 \%$ ) of the pure $\mathbf{2 n z}$ (pale white to buff fine powder) with M.P. $=294-296{ }^{\circ} \mathrm{C}$ (reported one $=290{ }^{\circ} \mathrm{C}[48]$ ).

\section{- HPLC analysis for separation of $2 n z$ and determination of its crude product purity:}

For these two purposes, the following HPLC analytical conditions were used:

- Column Type: SYMMETRY SHIELD RP C18 (250 × $4.6 \mathrm{~mm} ; 5 \mu \mathrm{m}$; equipped with Empower 2 software).

- Column Temperature: Ambient.

- Mobile Phase Constituents: $\mathrm{A}=\mathrm{MeOH} ; \mathrm{B}=0.1 \%$ TFA (trifluoroacetic acid) in $\mathrm{H}_{2} \mathrm{O}$.

- Diluent Constitution: ACN (acetonitrile) + TFA.

- Injection Volume: $2 \mu \mathrm{L}$.

- Flow Rate: $1 \mathrm{~mL} / \mathrm{min}$.

- Run Time: 20 min.

- Gradient Solvent System (Time (min)/A (\%)): 0/0; 6/0; 10/70; 18/70; 19/0;20/0.

- Wavelengths for UV Detection: 220 \& $272 \mathrm{~nm}$.

Table 7. Peak results of purity chromatogram for HPLC analysis of compound 2nz

\begin{tabular}{|c|c|c|}
\hline Fraction Isolated & Run Time (min) & \% Area \\
\hline I (2nz) & 7.716 & $\mathbf{9 8 . 9 9}$ \\
\hline II (Related Impurity 1) & 13.391 & 0.53 \\
\hline III (Related Impurity 2) & 13.678 & 0.03 \\
\hline IV (Related Impurity 3) & 14.258 & 0.27 \\
\hline V (Related Impurity 4) & 14.570 & 0.18 \\
\hline
\end{tabular}

Peak results of purity chromatogram for HPLC analysis of $\mathbf{2 n z}$ are shown above in Table 7 which shows that the percentage of pure $\mathbf{2 n z}$ in crude $\mathbf{2 n z}$ (obtained by both methods of synthesis) is about $99 \%$ (the major fraction isolated) and the percentage of related compounds (four fractions of impurities isolated) in it is only about $1 \%$ (i.e., the crude $2 \mathrm{nz}$ obtained is about $99 \%$ pure).

- Structure Elucidation of 2nz: IR $\left(v\right.$ in $\left.\mathrm{cm}^{-1}\right)$ : Str. $3429(\mathrm{O}-\mathrm{H})$, Str. 3393 \& $3299\left(2 \mathrm{~N}-\mathrm{H}\right.$, i.e., $\left.\mathrm{NH}_{2}\right), 3204$ (N-H, Amide), 2923 (C-H, Arom.), Str. 1606 (C=O, Amide), 1547 \& Str. 1501 \& 1467 (C=C, Arom.), 1286 (C-N, Aliph.), Str. 1209 (C-O), Str. 1055 (N-N); ${ }^{1} \mathrm{H}-\mathrm{NMR}$ (DMSO- $d_{6}, \delta$ in ppm): $2.000\left(\mathrm{~s}, 2 \mathrm{H}, \mathrm{NH}_{2}\right), 5.301(\mathrm{~s}, 3 \mathrm{H}, 3$ Arom. OH), 6.800 (s, 2H, 2 Benzene-H), 8.002 (s, 1H, Amide NH, i.e., Secondary Amide); ${ }^{13} \mathrm{C}-\mathrm{NMR}$ (DMSO- $d_{6}$, $\delta$ in ppm): 106.578 (2C, 2 Unsubstituted Arom. C), 123.624 (1C, 1 Arom. C-C=O), 136.285 (1C, 1 Arom. C-OH), 145.513 (2C, 2 Arom. C-OH), 166.528 (1C, 1 Amide C=O); MS ( $\mathrm{m} / \mathrm{z}$ (Rel. Int. in \%), M.Wt. = 184.15): $185.00(100.00)$, 166.98 (7.98), 152.92 (6.99), 128.03 (4.69), 126.83 (43.62), 113.78 (5.85); Elem. Anal. (\%, for $\left.\mathrm{C}_{7} \mathrm{H}_{8} \mathrm{~N}_{2} \mathrm{O}_{4}\right)$ : Calculated (Found): C: 45.66 (45.64), H: 4.38 (4.37), N: 15.21 (15.24).

\subsubsection{Synthesis of 5-(5-substituted-1,3,4-oxadiazol-2-yl)benzene-1,2, 3-triols (3n-z)}

The target compounds $\mathbf{3 n - z}$ were synthesized by the following two methods:

a- General Conventional Procedure (Method A): An ice-cooled mixture of $\mathbf{2 n z}(0.01$ mole, $1.8415 \mathrm{~g}$ if the carboxylic acid is monocarboxylic acid; 0.02 mole, 3.6830 $\mathrm{g}$ if the carboxylic acid is dicarboxylic acid; or 0.03 mole, $5.5245 \mathrm{~g}$ if the carboxylic acid is tricarboxylic acid) and the respective carboxylic acid (0.01 mole; see Table 3) was dissolved in dry $\mathrm{POCl}_{3}(5 \mathrm{~mL}$ if the carboxylic acid is monocarboxylic acid, $10 \mathrm{~mL}$ if the carboxylic acid is dicarboxylic acid, or $15 \mathrm{~mL}$ if the carboxylic acid is tricarboxylic acid; by dropwise addition of $\mathrm{POCl}_{3}$ to the mixture) and the resulted solution was gently heated under reflux (i.e., at about $105-110{ }^{\circ} \mathrm{C}$ ) with constant magnetic stirring for 3-9 $\mathrm{h}$ (see Table 3). The reaction was monitored and followed up by using TLC plates. When the reaction was over as indicated by TLC, the reaction mixture solution was concentrated in rotavap under reduced pressure, cooled to R.T., and then gradually and carefully poured onto crushed ice with stirring. The least amount required of finely powdered $\mathrm{K}_{2} \mathrm{CO}_{3}$ (potassium carbonate) and the required amount of solid $\mathrm{KOH}$ (potassium hydroxide) were added with stirring to the mixture solution till the $\mathrm{pH}$ of the solution was raised to 8 (it was measured by using pHmeter) to remove the excess of $\mathrm{POCl}_{3}$. The mixture solution was allowed to stand overnight till the solid was separated and completely precipitated. The separated crude solid was filtered, washed thoroughly with cold distilled $\mathrm{H}_{2} \mathrm{O}$, dried, and purified by recrystallization from an appropriate solvent or mixture of solvents (see for each compound below) to give the pure product $\mathbf{3}$ as shown below in details. 
b- General MW-assisted Procedure (Method B): An ice-cooled mixture of $\mathbf{2 n z}(0.01$ mole, $1.8415 \mathrm{~g}$ if the carboxylic acid is monocarboxylic acid; 0.02 mole, 3.6830 $\mathrm{g}$ if the carboxylic acid is dicarboxylic acid; or 0.03 mole, $5.5245 \mathrm{~g}$ if the carboxylic acid is tricarboxylic acid) and the respective carboxylic acid ( 0.01 mole; see Table 3$)$ was dissolved in dry $\mathrm{POCl}_{3}(5 \mathrm{~mL}$ if the carboxylic acid is monocarboxylic acid, $10 \mathrm{~mL}$ if the carboxylic acid is dicarboxylic acid, or $15 \mathrm{~mL}$ if the carboxylic acid is tricarboxylic acid; by dropwise addition of $\mathrm{POCl}_{3}$ to the mixture); acidic alumina ( $5 \mathrm{~g}$ if the carboxylic acid is monocarboxylic acid, $10 \mathrm{~g}$ if the carboxylic acid is dicarboxylic acid, or $15 \mathrm{~g}$ if the carboxylic acid is tricarboxylic acid) was added to the above-resulted solution at R.T.; and the resulted paste of reaction mixture was well mixed, adsorbed, dried, kept inside the alumina bath, covered with aluminum foil, and subjected to intermittent MWI at intervals of 30 s for 4-10 min at a power level of $300-800 \mathrm{~W}$ (see Table 3). The reaction was monitored and followed up by using TLC plates till it was over. After cooling the reaction mixture to R.T., a suitable amount of anhydrous $\mathrm{CH}_{2} \mathrm{Cl}_{2}$ was added to this mixture to efficiently dissolve the acidic alumina; the $\mathrm{CH}_{2} \mathrm{Cl}_{2}$ layer was evaporated in rotavap under reduced pressure to completely remove the acidic alumina from the reaction mixture; the remaining crude paste was cooled to R.T. and then gradually poured with care onto crushed ice with stirring. The least amount required of finely powdered $\mathrm{K}_{2} \mathrm{CO}_{3}$ and the required amount of solid $\mathrm{KOH}$ were added with stirring to the mixture solution till the $\mathrm{pH}$ of the solution was raised to 8 (it was measured by using pHmeter) to remove the excess of $\mathrm{POCl}_{3}$. The mixture solution was allowed to stand overnight till the solid was separated and completely settled down. The separated crude solid was filtered, washed thoroughly with cold distilled $\mathrm{H}_{2} \mathrm{O}$, dried, and purified by recrystallization from an appropriate solvent(s) (see for each compound below) to give the pure product $\mathbf{3}$ as shown below in details.

- 5-(5-Pentadecyl-1,3,4-oxadiazol-2-yl)benzene-1,2, 3-triol (3n): Recryst. from benzene; Col. \& App.: pale buff fine powder; Yield: $94.0 \%$ (Conv.), 99.2\% (MW); M.P.: $114{ }^{\circ} \mathrm{C}$; IR (v in cm ${ }^{-1}$ ): Str. \& Bro. $3452(\mathrm{O}-\mathrm{H})$, Str. 3129 (C-H, Arom.), Str. 2909 (C-H, Aliph.), 1660 (C=N), 1532 \& 1519 \& 1377 (C=C, Arom.), Str. 1263 \& Str. 1137 (C-O), Str. $1063(\mathrm{~N}-\mathrm{N}) ;{ }^{1} \mathrm{H}-\mathrm{NMR}$ (DMSO- $d_{6}, \delta$ in ppm): 0.843-0.932 (t, $J=8.0 \mathrm{~Hz}, 3 \mathrm{H}$, Terminal $\left.\mathrm{CH}_{3}\right), 1.259-1.679$ (m, 26H, All Other $13 \mathrm{CH}_{2}$ ), 2.495-2.513 (t, $J=7.1 \mathrm{~Hz}, 2 \mathrm{H}$, $\alpha-\mathrm{CH}_{2}$ to Oxadiazole Ring), 5.391 (s, 3H, 3 Arom. OH), 6.785-7.313 (s, 2H, 2 Benzene-H); MS ( $\mathrm{m} / \mathrm{z}$ (Rel. Int. in \%), M.Wt. = 404.54): 405.10 (8.90), 388.10 (8.28), 280.10 (10.12), 125.10 (17.33), 69.00 (52.45), 57.05 (100.00); Elem. Anal. (\%, for $\mathrm{C}_{23} \mathrm{H}_{36} \mathrm{~N}_{2} \mathrm{O}_{4}$ ): Calculated (Found): C: 68.29 (68.18), H: 8.97 (8.93), N: 6.92 (6.93).

- 5-[5-(1-Hydroxyethyl)-1,3,4-oxadiazol-2-yl]benzene1,2,3-triol (3o): Recryst. from abs. EtOH/ $\mathrm{H}_{2} \mathrm{O}(3: 1, v / v)$; Col. \& App.: greyish green fine powder; Yield: $92.0 \%$ (Conv.), $98.0 \%$ (MW); M.P.: $>300{ }^{\circ} \mathrm{C}$; IR $\left(v\right.$ in $\left.\mathrm{cm}^{-1}\right)$ : Str.
\& Bro. 3452 (O-H), Str. 3094 (C-H, Arom.), Str. 2922 (C-H, Aliph.), Str. 1579 (C=N), 1505 \& 1466 \& 1401 \& Str. 1371 $\left(\mathrm{C}=\mathrm{C}\right.$, Arom.), Str. 1263 (C-O), Str. $1048(\mathrm{~N}-\mathrm{N}) ;{ }^{1} \mathrm{H}-\mathrm{NMR}$ $\left(\mathrm{CDCl}_{3}, \delta\right.$ in ppm): $1.267-1.582\left(\mathrm{~d}, J=6.8 \mathrm{~Hz}, 3 \mathrm{H}, \mathrm{CH}_{3}\right)$, 3.653 (s, 1H, Aliph. OH), 4.676-4.686 (q, $J=6.8 \mathrm{~Hz}, 1 \mathrm{H}$, $\mathrm{CH}), 5.373(\mathrm{~s}, 3 \mathrm{H}, 3$ Arom. OH), $7.272(\mathrm{~s}, 2 \mathrm{H}, 2$ Benzene-H); MS ( $\mathrm{m} / \mathrm{z}$ (Rel. Int. in \%), M.Wt. = 238.20): 238.25 (1.70), 221.20 (0.99), 125.15 (13.89), 113.15 (15.33), 69.05 (35.66), 57.05 (100.00); Elem. Anal. (\%, for $\mathrm{C}_{10} \mathrm{H}_{10} \mathrm{~N}_{2} \mathrm{O}_{5}$ ): Calculated (Found): C: 50.42 (50.46), H: 4.23 (4.24), N: 11.76 (11.73).

- 5-[5-(Dichloromethyl)-1,3,4-oxadiazol-2-yl]benzene1,2,3-triol (3p): Recryst. from EtOAc; Col. \& App.: dark brownish green fine powder; Yield: $90.3 \%$ (Conv.), 97.3\% (MW); M.P.: $>300{ }^{\circ} \mathrm{C}$; IR $\left(v\right.$ in $\left.\mathrm{cm}^{-1}\right)$ : Str. \& Bro. 3372 (O-H), Str. 2922 (C-H, Arom.), Str. 2850 (C-H, Aliph.), Str. $1678(\mathrm{C}=\mathrm{N})$, Str. 1578 \& Str. 1509 \& Str. 1465 \& Str. 1404 \& Str. 1373 (C=C, Arom.), 1242 \& Str. 1199 (C-O), Str. $1051(\mathrm{~N}-\mathrm{N}), 766 \& 750(\mathrm{C}-\mathrm{Cl}) ;{ }^{1} \mathrm{H}-\mathrm{NMR}\left(\mathrm{CDCl}_{3}, \delta\right.$ in $\left.\mathrm{ppm}\right)$ : 5.548 (s, 3H, 3 Arom. OH), 7.272 (2 Overlapped s, 3H, 2 Benzene-H \& CH); MS ( $\mathrm{m} / z$ (Rel. Int. in \%), M.Wt. = 277.06): 277.25 (2.01), 152.15 (2.02), 125.15 (17.89), 83.10 (33.62), 69.05 (39.41), 57.05 (100.00); Elem. Anal. (\%, for $\mathrm{C}_{9} \mathrm{H}_{6} \mathrm{Cl}_{2} \mathrm{~N}_{2} \mathrm{O}_{4}$ ): Calculated (Found): C: 39.02 (39.01), H: 2.18 (2.18), N: 10.11 (10.10).

- 5-[5-Trichloromethyl)-1,3,4-oxadiazol-2-yl]benzene-1,2,-triol (3q): Recryst. from EtOAc; Col. \& App.: pale white crystalline powder; Yield: $89.1 \%$ (Conv.), 96.4\% (MW); M.P.: $56-58^{\circ} \mathrm{C}$; IR (v in $\left.\mathrm{cm}^{-1}\right)$ : Str. \& Bro. $3466(\mathrm{O}-\mathrm{H})$, Str. 2922 (C-H, Arom.), Str. 1667 \& Str. $1633(\mathrm{C}=\mathrm{N}), 1557$ \& 1538 \& $1514 \& 1504 \& 1463$ (C=C, Arom.), Str. 1199 (C-O), Str. $1077(\mathrm{~N}-\mathrm{N})$, Str. $868(\mathrm{C}-\mathrm{Cl}) ;{ }^{1} \mathrm{H}-\mathrm{NMR}\left(\mathrm{CDCl}_{3}, \delta\right.$ in ppm): 5.359 (s, 3H, 3 Arom. OH), 7.270 (s, 2H, 2 Benzene-H); MS ( $/ 2 / z$ (Rel. Int. in \%), M.Wt. = 311.51): 311.10 (33.20), 294.10 (23.08), 187.10 (8.91), 125.15 (2.02), 69.05 (28.34), 59.00 (100.00); Elem. Anal. (\%, for $\left.\mathrm{C}_{9} \mathrm{H}_{5} \mathrm{Cl}_{3} \mathrm{~N}_{2} \mathrm{O}_{4}\right)$ : Calculated (Found): C: 34.70 (34.77), H: 1.62 (1.61), N: 8.99 (8.95).

- (S)-5-[5-(1-Amino-2-phenylethyl)-1,3,4-oxadiazol-2yl]benzene-1,2,3-triol (3r): Recryst. from $D E E / a b s$. $E t O H$ (3:1, v/v); Col. \& App.: pale white minute crystalline plates; Yield: $83.5 \%$ (Conv.), 97.9\% (MW); M.P.: 256-258 ${ }^{\circ} \mathrm{C}$ (dec.); IR (v in $\left.\mathrm{cm}^{-1}\right)$ : Str. \& Bro. $3427(\mathrm{O}-\mathrm{H})$, Str. 3388 \& Str. 3299 (2 N-H, i.e., $\mathrm{NH}_{2}$ ), Str. 2922 (C-H, Arom.), Str. 2850 (C-H, Aliph.), 1663 (C=N), Str. 1607 \& 1548 \& Str. $1500 \& 1467 \& 1367$ (C=C, Arom.), 1286 (C-N, Aliph.), $1211(\mathrm{C}-\mathrm{O})$, Str. $1078(\mathrm{~N}-\mathrm{N}) ;{ }^{1} \mathrm{H}-\mathrm{NMR}$ (DMSO- $d_{6}, \delta$ in ppm): 3.073-3.087 \& 3.097-3.112 (2 dd, $J=-12.4 \mathrm{~Hz} \& 7.0$ $\mathrm{Hz}, 2$ Diastereotopic $\left.\mathrm{H}, \mathrm{CH}_{2}\right), 4.351(\mathrm{t}, J=7.0 \mathrm{~Hz}, 1 \mathrm{H}, \mathrm{CH})$, 5.113 (s, 2H, Aliph. $\mathrm{NH}_{2}$ ), 5.364 (s, 3H, 3 Arom. $\mathrm{OH}$ ), 6.787 (s, 2H, 2 Benzene-H), 7.275-7.327 (m, 5H, 1 p- \& 2 $o$ - \& $2 \mathrm{~m}$-Benzene-H); MS ( $\mathrm{m} / \mathrm{z}$ (Rel. Int. in \%), M.Wt. = 313.31): 313.10 (2.44), 222.00 (26.99), 153.00 (100.00), 125.05 (38.21), 91.05 (63.36), 69.00 (2.73); Elem. Anal. (\%, for $\mathrm{C}_{16} \mathrm{H}_{15} \mathrm{~N}_{3} \mathrm{O}_{4}$ ): Calculated (Found): C: 61.34 (61.39), $\mathrm{H}$ : 4.83 (4.80), N: 13.41 (13.41). 
- 5,5'-[5,5'-Methylenebis(1,3,4-oxadiazole-5,2-diyl)]dibenzene-1,2,3-triol (3s): Recryst. from DMF/abs. EtOH $(2: 1, v / v)$; Col. \& App.: whitish buff crystalline powder; Yield: $84.0 \%$ (Conv.), $95.0 \%$ (MW); M.P.: $>300{ }^{\circ} \mathrm{C}$; IR (v in $\left.\mathrm{cm}^{-1}\right)$ : Str. \& Bro. 3424 (O-H), 2922 (C-H, Arom.), 2850 (C-H, Aliph.), $1659 \& 1651(\mathrm{C}=\mathrm{N}), 1615 \& 1548$ \& 1538 \& $1504 \& 1469 \& 1455$ (C=C, Arom.), 1285 \& 1208 (C-O), Str. $1083(\mathrm{~N}-\mathrm{N})$; ${ }^{1} \mathrm{H}-\mathrm{NMR}$ (DMSO- $d_{6}, \delta$ in $\mathrm{ppm}$ ): 3.366-4.276 (s, 2H, $\left.\mathrm{CH}_{2}\right), 5.368$ (s, 6H, 6 Arom. OH), 6.777-6.781 (s, 4H, 4 Benzene-H); MS ( $\mathrm{m} / \mathrm{z}$ (Rel. Int. in \%), M.Wt. = 400.30): 400.10 (18.29), 109.10 (19.54), 83.10 (31.08), 69.10 (42.27), 57.05 (100.00), 55.00 (51.87); Elem. Anal. (\%, for $\mathrm{C}_{17} \mathrm{H}_{12} \mathrm{~N}_{4} \mathrm{O}_{8}$ ): Calculated (Found): C: 51.01 (51.09), H: 3.02 (3.03), N: 14.00 (14.04).

- 5,5'-\{5,5'-[(1R,2R)-1,2-Dihydroxyethane-1,2-diyl]bis(1,3, 4-oxadiazole-5,2-diyl)\}dibenzene-1,2,3-triol (3t): Recryst. from DMF/abs. EtOH $(2: 1, v / v)$; Col. \& App.: brownish orange fine powder; Yield: $75.0 \%$ (Conv.), $97.0 \%$ (MW); M.P.: $198-200{ }^{\circ} \mathrm{C}$; IR $\left(v\right.$ in $\left.\mathrm{cm}^{-1}\right)$ : Str. \& Bro. $3416(\mathrm{O}-\mathrm{H})$, Str. 2972 (C-H, Arom.), Str. 2850 (C-H, Aliph.), Str. 1682 \& Str. $1616(\mathrm{C}=\mathrm{N}), 1551 \& 1538$ \& 1531 \& 1515 \& 1449 \& $1398(\mathrm{C}=\mathrm{C}$, Arom.), Str. 1240 \& 1186 (C-O), 1099 \& Str. $1030(\mathrm{~N}-\mathrm{N}) ;{ }^{1} \mathrm{H}-\mathrm{NMR}\left(\mathrm{CDCl}_{3}, \delta\right.$ in ppm): $3.655(\mathrm{~s}, 2 \mathrm{H}, 2$ Aliph. OH), 4.918-4.971 (d, $J=7 \mathrm{~Hz}, 2 \mathrm{H}, 2 \mathrm{CH}), 5.375$ (s, 6H, 6 Arom. OH), 7.259-7.272 (s, 4H, 4 Benzene-H); MS $(\mathrm{m} / \mathrm{z}$ (Rel. Int. in \%), M.Wt. = 446.32): 447.00 (9.91), 446.00 (7.73), 125.00 (27.95), 79.95 (100.00), 69.00 (42.61), 57.05 (73.13); Elem. Anal. $\left(\%\right.$, for $\left.\mathrm{C}_{18} \mathrm{H}_{14} \mathrm{~N}_{4} \mathrm{O}_{10}\right)$ : Calculated (Found): C: 48.44 (48.48), H: 3.16 (3.14), N: 12.55 (12.53).

- 1,2,3-Tris[5-(3,4,5-trihydroxyphenyl)-1,3,4-oxadiazol-2yl]propan-2-ol (3u): Recryst. from abs. $\mathrm{EtOH} / \mathrm{H}_{2} \mathrm{O}(3: 1, \mathrm{v} / \mathrm{v})$; Col. \& App.: brown crystalline powder; Yield: $90.0 \%$ (Conv.), 99.0\% (MW); M.P.: 99-100 ${ }^{\circ} \mathrm{C}$ (dec.); IR (v in $\left.\mathrm{cm}^{-1}\right)$ : Str. \& Bro. $3460(\mathrm{O}-\mathrm{H}), 2917$ (C-H, Arom.), 2850 (C-H, Aliph.), Str. 1637 (C=N), 1489 \& 1389 (C=C, Arom.), $1262(\mathrm{C}-\mathrm{O})$, Str. $1071(\mathrm{~N}-\mathrm{N})$; ${ }^{1} \mathrm{H}-\mathrm{NMR}$ (DMSO- $d_{6}, \delta$ in ppm): 2.495-2.507 (s, 4H, $2 \mathrm{CH}_{2}$ ), 3.338 (s, $1 \mathrm{H}$, Aliph. $\mathrm{OH}$ ), 5.373 (s, 9H, 9 Arom. OH), 7.270 (s, 6H, 6 Benzene-H); MS $(\mathrm{m} / \mathrm{z}$ (Rel. Int. in \%), M.Wt. = 636.48): 636.00 (4.35), 443.00 (3.38), 125.00 (5.69), 69.00 (22.54), 63.95 (100.00), 57.05 (37.95); Elem. Anal. (\%, for $\left.\mathrm{C}_{27} \mathrm{H}_{20} \mathrm{~N}_{6} \mathrm{O}_{13}\right)$ : Calculated (Found): C: 50.95 (50.96), H: 3.17 (3.16), N: $13.20(13.21)$.

- (E)-5-(5-Styryl-1,3,4-oxadiazol-2-yl)benzene-1,2,3-triol (3v): Recryst. from abs. $\mathrm{EtOH} / \mathrm{H}_{2} \mathrm{O}(3: 1, \mathrm{v} / \mathrm{v})$; Col. \& App.: brownish green crystalline powder; Yield: $73.0 \%$ (Conv.), 97.5\% (MW); M.P.: $299-300{ }^{\circ} \mathrm{C}$ (dec.); IR (v in $\left.\mathrm{cm}^{-1}\right)$ : Str. \& Bro. $3445(\mathrm{O}-\mathrm{H})$, Str. 3080 \& Str. 3055 (=C-H, Alkene), Str. 2918 (C-H, Arom.), Str. 1641 (C=C, Alkene), 1578 $(\mathrm{C}=\mathrm{N}), 1556$ \& Str. 1514 \& Str. 1450 \& Str. $1387(\mathrm{C}=\mathrm{C}$, Arom.), 1257 \& 1230 \& 1203 (C-O), Str. 1072 (N-N); ${ }^{1} \mathrm{H}-\mathrm{NMR}$ (DMSO- $d_{6}, \delta$ in ppm): 5.351 (s, $3 \mathrm{H}, 3$ Arom. OH), 6.787 (s, 2H, 2 Benzene-H), $6.955 \& 7.029$ ( $2 \mathrm{~d}, J=15.1$ $\mathrm{Hz}, 2 \mathrm{H}$, trans $\mathrm{HC}=\mathrm{CH}), 7.282-7.327(\mathrm{~m}, 5 \mathrm{H}, 1 \mathrm{p}-\& 2 \mathrm{~m}-\&$ $2 o$-Benzene-H); MS ( $\mathrm{m} / \mathrm{z}($ Rel. Int. in \%), M.Wt. $=296.28)$ : 296.10 (0.83), 153.00 (100.00), 125.05 (38.21), 103.05
(6.93), 77.00 (7.06), 69.00 (2.73); Elem. Anal. (\%, for $\mathrm{C}_{16} \mathrm{H}_{12} \mathrm{~N}_{2} \mathrm{O}_{4}$ ): Calculated (Found): C: 64.86 (64.80), H: 4.08 (4.09), N: 9.46 (9.49).

- (E)-5,5'-[5,5'-(Ethene-1,2-diyl)bis(1,3,4-oxadiazole-5, 2-diyl)]dibenzene-1,2,3-triol (3w): Recryst. from abs. $\mathrm{MeOH}$; Col. \& App.: light brown fine powder; Yield: 93.2\% (Conv.), 98.8\% (MW); M.P.: $288-290{ }^{\circ} \mathrm{C}$ (dec.); IR $\left(v\right.$ in $\left.\mathrm{cm}^{-1}\right)$ : Str. \& Bro. $3425(\mathrm{O}-\mathrm{H})$, Str. 3077 \& Str. 3054 (=C-H, Alkene), Str. 2926 (C-H, Arom.), Str. $1602(\mathrm{C}=\mathrm{C}$, Alkene), $1546(\mathrm{C}=\mathrm{N}), 1505 \& 1467 \& 1413 \& 1373(\mathrm{C}=\mathrm{C}$, Arom.), 1286 \& 1206 (C-O), Str. 1078 \& Str. 1057 (N-N); ${ }^{1} \mathrm{H}-\mathrm{NMR}\left(\mathrm{CDCl}_{3}, \delta\right.$ in ppm): 5.362 (s, $6 \mathrm{H}, 6$ Arom. $\left.\mathrm{OH}\right)$, $6.776(\mathrm{~s}, 4 \mathrm{H}, 4$ Benzene-H), $6.788(\mathrm{~d}, J=15.1 \mathrm{~Hz}, 2 \mathrm{H}$, trans $\mathrm{HC}=\mathrm{CH})$; $\mathrm{MS}(\mathrm{m} / \mathrm{z}$ (Rel. Int. in \%), M.Wt. $=412.31)$ : 412.10 (19.36), 111.10 (22.38), 95.10 (20.60), 71.10 (53.82), 69.10 (42.27), 57.05 (100.00); Elem. Anal. (\%, for $\mathrm{C}_{18} \mathrm{H}_{12} \mathrm{~N}_{4} \mathrm{O}_{8}$ ): Calculated (Found): C: 52.43 (52.47), H: 2.93 (2.92), N: 13.59 (13.57).

- 5-[5-(4-Bromophenyl)-1,3,4-oxadiazol-2-yl]benzene1,2,3-triol (3x): Recryst. from abs. EtOH; Col. \& App.: buff crystalline powder; Yield: $82.8 \%$ (Conv.), $96.0 \%$ (MW); M.P.: $>300{ }^{\circ} \mathrm{C}$; IR (v in $\mathrm{cm}^{-1}$ ): Str. \& Bro. 3476 (O-H), Str. 3066 (C-H, Arom.), $1637(\mathrm{C}=\mathrm{N}), 1551$ \& 1517 \& $1499 \& 1374(\mathrm{C}=\mathrm{C}$, Arom.), 1189 (C-O), Str. 1079 $(\mathrm{N}-\mathrm{N})$, Str. $530(\mathrm{C}-\mathrm{Br}) ;{ }^{1} \mathrm{H}-\mathrm{NMR}$ (DMSO- $d_{6}, \delta$ in ppm): $5.382(\mathrm{~s}, 3 \mathrm{H}, 3$ Arom. OH), 6.785-6.882 (s, 2H, 2 Benzene-H), 7.305-7.313 (m, 4H, 4 Benzene-H); MS ( $\mathrm{m} / \mathrm{z}$ $($ Rel. Int. in \%), M.Wt. = 349.14): 349.10 (8.90), 193.10 (10.12), 157.10 (10.74), 125.10 (17.33), 69.00 (52.45), 57.05 (100.00); Elem. Anal. (\%, for $\left.\mathrm{C}_{14} \mathrm{H}_{9} \mathrm{BrN}_{2} \mathrm{O}_{4}\right)$ : Calculated (Found): C: 48.16 (48.12), H: 2.60 (2.63), N: 8.02 (8.06).

- 5,5'-(1,3,4-Oxadiazole-2,5-diyl)dibenzene-1,2,3-triol (3y): Recryst. from abs. EtOH/H $\mathrm{H}_{2} \mathrm{O}(3: 1, \mathrm{v} / \mathrm{v})$; Col. \& App.: brown crystalline powder; Yield: $88.0 \%$ (Conv.), $98.2 \%$ (MW); M.P.: 82-84 ${ }^{\circ} \mathrm{C}$; IR (v in $\left.\mathrm{cm}^{-1}\right)$ : Str. \& Bro. 3466 (O-H), Str. 3090 (C-H, Arom.), 1647 (C=N), 1553 \& 1533 \& 1468 \& $1380(\mathrm{C}=\mathrm{C}$, Arom.), 1199 (C-O), Str. 1071 $(\mathrm{N}-\mathrm{N}) ;{ }^{1} \mathrm{H}-\mathrm{NMR}\left(\mathrm{CDCl}_{3}, \delta\right.$ in ppm): 5.333 (s, 6H, 6 Arom. $\mathrm{OH}), 6.736$ (s, 4H, 4 Benzene-H); MS ( $\mathrm{m} / \mathrm{z}$ (Rel. Int. in \%), M.Wt. = 318.24): 318.10 (2.44), 193.00 (0.90), 153.00 (100.00), 125.05 (38.21), 69.00 (2.73), 57.00 (2.59); Elem. Anal. (\%, for $\mathrm{C}_{14} \mathrm{H}_{10} \mathrm{~N}_{2} \mathrm{O}_{7}$ ): Calculated (Found): C: 52.84 (52.91), H: 3.17 (3.15), N: 8.80 (8.76).

- 5-[5-7-Chloro-4hydroxyquinolin-3-yl)-1,3,40xadiazol-2-y]]benzene1,23-triol (3z): Recryst. from hexane; Col. \& App.: brownish buff fine powder; Yield: $86.4 \%$ (Conv.), 95.5\% (MW); M.P.: $60-61{ }^{\circ} \mathrm{C}$ (dec.); IR (v in $\left.\mathrm{cm}^{-1}\right)$ : Str. \& Bro. 3467 $(\mathrm{O}-\mathrm{H})$, Str. 3100 (C-H, Arom.), Str. $1620(\mathrm{C}=\mathrm{N}), 1533$ \& $1483 \& 1457 \& 1378$ (C=C, Arom.), Str. 1081 (C-O), Str. $983(\mathrm{~N}-\mathrm{N}), 869(\mathrm{C}-\mathrm{Cl}) ;{ }^{1} \mathrm{H}-\mathrm{NMR}$ (DMSO- $d_{6}, \delta$ in ppm): 5.337 (s, 4H, 4 Arom. OH), 6.716 (s, 2H, 2 Benzene-H), 7.707 (dd, $J=7.5 \mathrm{~Hz} \& 1.5 \mathrm{~Hz}, 1 \mathrm{H}$, Quinoline-H-7), 7.949 (d, $J=1.5 \mathrm{~Hz}, 1 \mathrm{H}$, Quinoline-H-9), $8.406 \& 8.428(\mathrm{~d} \& \mathrm{~s}$, $J_{\mathrm{H}-6}=7.5 \mathrm{~Hz}, 2 \mathrm{H}$, Quinoline-H-6,2); MS ( $\mathrm{m} / \mathrm{z}$ (Rel. Int. in \%), M.Wt. = 371.73): 371.10 (9.51), 193.10 (10.12), 144.10 (9.20), 129.10 (28.07), 69.00 (52.45), 57.05 (100.00); 
Elem. Anal. (\%, for $\mathrm{C}_{17} \mathrm{H}_{10} \mathrm{ClN}_{3} \mathrm{O}_{5}$ ): Calculated (Found): C: 54.93 (54.91), H: 2.71 (2.72), N: 11.30 (11.33).

\subsection{Biological Evaluation}

\subsubsection{ABTS Test}

All reagents and L-ascorbic acid were purchased from Aldrich Chemical Co., U.S.A.; while pure EtOH (of very high analytical grade) was purchased from El-Nasr Co. for Pharmaceutical Chemicals, Egypt. This assay was done according to the original idea of Re et al. [55] with very slight modifications. 2,2'-Azinobis(3-ethylbenzothiazoline6-sulfonic acid) radical cation $\left(\mathrm{ABTS}^{+}\right)$is a free and stable radical cation which is able to react with any compound that can give a hydrogen atom or an electron (i.e., antioxidants, such as phenols and thiols), with decolorization of its dark green color. ABTS test is usually used to evaluate the antioxidant capacity of the biological fluids and many pure organic compounds.

The $\mathrm{ABTS}^{+}$radical cation (blue-dark green) was prepared by reacting (i.e., mixing) equal volumes of ABTS stock solution (colorless; $7 \mathrm{mM}$ in pure distilled $\mathrm{H}_{2} \mathrm{O}$ ) and $\mathrm{K}_{2} \mathrm{~S}_{2} \mathrm{O}_{8}$ stock solution (potassium persulfate; $3.5 \mathrm{mM}$ in pure distilled $\mathrm{H}_{2} \mathrm{O}$ ) (ABTS and $\mathrm{K}_{2} \mathrm{~S}_{2} \mathrm{O}_{8}$ react stoichiometrically at a ratio of $2: 1$, respectively). The mixture was kept and allowed to stand in the dark at R.T. overnight (i.e., for about $12-16 \mathrm{~h}$ in the darkness) until the reaction was complete and the strong spectrophotometric absorbance (under UV) at a wavelength of $734 \mathrm{~nm}$ reaches the maximal stable value to obtain the $\mathrm{ABTS}^{+}$stock solution which is valid for use in this form for about 2-3 days when stored in the dark at R.T. The $\mathrm{ABTS}^{+}$working solution was prepared by diluting the $\mathrm{ABTS}^{+}$stock solution in pure $\mathrm{EtOH}$ to have an absorbance $\left(\mathrm{A}_{\text {blank }}\right)$ of $0.7 \pm 0.02$ (after three times of measurement) at a wavelength of 734 $\mathrm{nm}$ and the solution was equilibrated with a temperature control set at $30{ }^{\circ} \mathrm{C}$ in an incubator $\left(\mathrm{A}_{\text {blank }}\right.$ was adjusted in this present assay to be exactly 0.7 before measuring the absorbance for all the test compounds). Free radical scavenging activity was assessed by mixing $1.5 \mathrm{~mL}$ of the blue-green $\mathrm{ABTS}^{+}$working solution with $10 \mu \mathrm{L}$ of the solutions of the target test compounds (3n-z) at various concentrations ranging from 10 to $300 \mu \mathrm{M}$ (in distilled $\mathrm{H}_{2} \mathrm{O}$, pure $\mathrm{EtOH}$, or mixture of both of them according to the solubility of each compound). The change in absorbance at $734 \mathrm{~nm}$ was immediately monitored at $0,0.5,1 \mathrm{~min}$ after the addition (i.e., after the mixing) and again at $5 \mathrm{~min}$ intervals until a steady-state value was obtained. The steady state was achieved after $15 \mathrm{~min}$ in this present assay, so the absorbance value for each test compound after its addition to $\mathrm{ABTS}^{+}$solution $\left(\mathrm{A}_{\text {test }}\right)$ was taken after $15 \mathrm{~min}$ of their mixing. Values are means of three independent determinations (as all the measurements were taken three independent times after each period for each concentration of each test compound). The percent reduction in absorbance (which represents the $\mathrm{ABTS}^{+}$radical cation scavenging activity of the test compound) was calculated according to the following equation:

$$
\begin{aligned}
& \mathrm{ABTS}^{+} \text {radical cation scavenging activity of test } \\
& \text { compound }(\%)=100\left(\mathrm{~A}_{\text {blank }}-\mathrm{A}_{\text {test }}\right) / \mathrm{A}_{\text {blank }} \text {. }
\end{aligned}
$$

Where, $\mathrm{A}_{\text {blank }}$ or $\mathrm{A}_{0}$ is the absorbance of $\mathrm{ABTS}^{+}$radical cation in $\mathrm{H}_{2} \mathrm{O}$ and $\mathrm{EtOH}$ directly before reaction time $=0$ min, i.e., directly before adding the test compound to the $\mathrm{ABTS}^{+}$radical cation $\left(\mathrm{A}_{\text {blank }}\right.$ was adjusted to be 0.70 ), while $\mathrm{A}_{\text {test }}$ or $\mathrm{A}_{15}$ is the absorbance of the $\mathrm{ABTS}^{+}$radical cation (or of the reaction mixture) in $\mathrm{H}_{2} \mathrm{O}$ and $\mathrm{EtOH}$ at reaction time $=15 \mathrm{~min}$, i.e., after $15 \mathrm{~min}$ of adding the test compound to the $\mathrm{ABTS}^{+}$radical cation. For each of the test compounds, the $\mathrm{IC}_{50}$ (the inhibitory concentration $50 \%$, it is the concentration of any test compound needed to inhibit or reduce the absorption or the amount of $\mathrm{ABTS}^{+}$radical cations by $50 \%$ at a wavelength of $734 \mathrm{~nm}$ ) was determined after $15 \mathrm{~min}$ of reaction and compared to that of L-ascorbic acid (taken as the reference and standard antioxidant compound in this assay). The antioxidant or anti-ABTS ${ }^{+}$ $\mathrm{IC}_{50}$ value (for each test compound along with the reference L-ascorbic acid) was calculated using GraphPad Prism 6 software (U.S.A., 2015) and the lower the $\mathrm{IC}_{50}$ value is, the more powerful the test compound as antioxidant is (i.e., the stronger the antioxidant capacity of the test compound is).

\subsubsection{DPPH Test}

DPPH, L-ascorbic acid, and trolox were purchased from Aldrich Chemical Co., U.S.A.; while pure EtOH (of very high analytical grade) was purchased from El-Nasr Co. for Pharmaceutical Chemicals, Egypt. This assay was done according to the procedure described by Prouillac et al. [56]. The ability of phenolic/thiol derivatives to donate a hydrogen atom was also evaluated by their ability to react with the stable 2,2-diphenyl-1-picrylhydrazyl free radical (DPPH). DPPH free radicals show a strong absorption band (dark red-violet color) at $516 \mathrm{~nm}$ and become colorless on reduction (i.e., their absorption band color fades away upon the absorption band reduction by a free radical scavenger compound). DPPH test is, exactly like ABTS test, used to evaluate the antioxidant capacity of the biological fluids and many pure compounds.

The target test 1,3,4-oxadiazole derivatives (compounds $3 \mathbf{n}-\mathbf{z}$ ) were added at various concentrations, varying from 5 to $150 \mu \mathrm{M}$ in pure $\mathrm{EtOH}$ or aqueous EtOH solution (according to the solubility of each test compound), to a freshly prepared ethanolic solution of DPPH $(80 \mu \mathrm{M})$. The absorbance was firstly measured at $516 \mathrm{~nm}$ at time $=0 \mathrm{~min}$ (i.e., directly before adding the solution of the test compound to the DPPH solution) $\left(\mathrm{A}_{0}\right)$ and after $30 \mathrm{~min}$ of incubation at R.T. (i.e., after $30 \mathrm{~min}$ of adding the test compound to the DPPH solution and beginning the reaction) $\left(\mathrm{A}_{30}\right)$. Values are means of three independent determinations (as all the experiments were carried out in triplicate) and the percent reduction in absorbance or the percent inhibition of DPPH free radical (which represents the DPPH free radical scavenging activity of the test compound) (I\%) was calculated in the following way: 


$$
\mathrm{I} \%=100\left(\mathrm{~A}_{0}-\mathrm{A}_{30}\right) / \mathrm{A}_{0} .
$$

For each of the test compounds, the $\mathrm{IC}_{50}$ (the inhibitory concentration $50 \%$, it is the concentration of any test compound needed to inhibit or reduce the absorption or the amount of DPPH free radicals by $50 \%$ at a wavelength of $516 \mathrm{~nm}$ ) was determined after $30 \mathrm{~min}$ of reaction and compared to those of L-ascorbic acid and trolox (both were standardized as the reference antioxidant compounds in this assay). The antioxidant or anti-DPPH $\mathrm{IC}_{50}$ value (for each of the test compounds along with the two references L-ascorbic acid and trolox) was calculated using GraphPad Prism 6 software (U.S.A., 2015) and the less the $\mathrm{IC}_{50}$ value is, the more potent and active the test compound as antioxidant is.

\section{ACKNOWLEDGMENTS}

We are thankful to the staff members of the Departments of Pharmaceutical Organic Chemistry, Medicinal Chemistry, Pharmacognosy, and Pharmacology \& Toxicology (Faculty of Pharmacy, Mansoura University, Mansoura, Egypt) for their support and interest in this new research. We are also very grateful to $\mathrm{Mr}$. Ahmed A. Ibrahim (a laboratory technician at the Department of Pharmacognosy, Faculty of Pharmacy, Mansoura University, Mansoura, Egypt) for his technical help in the in vitro antioxidant assays.

\section{Appendix A}

\section{Chemical Structures and IUPAC Nomenclature of All the Research Compounds:}

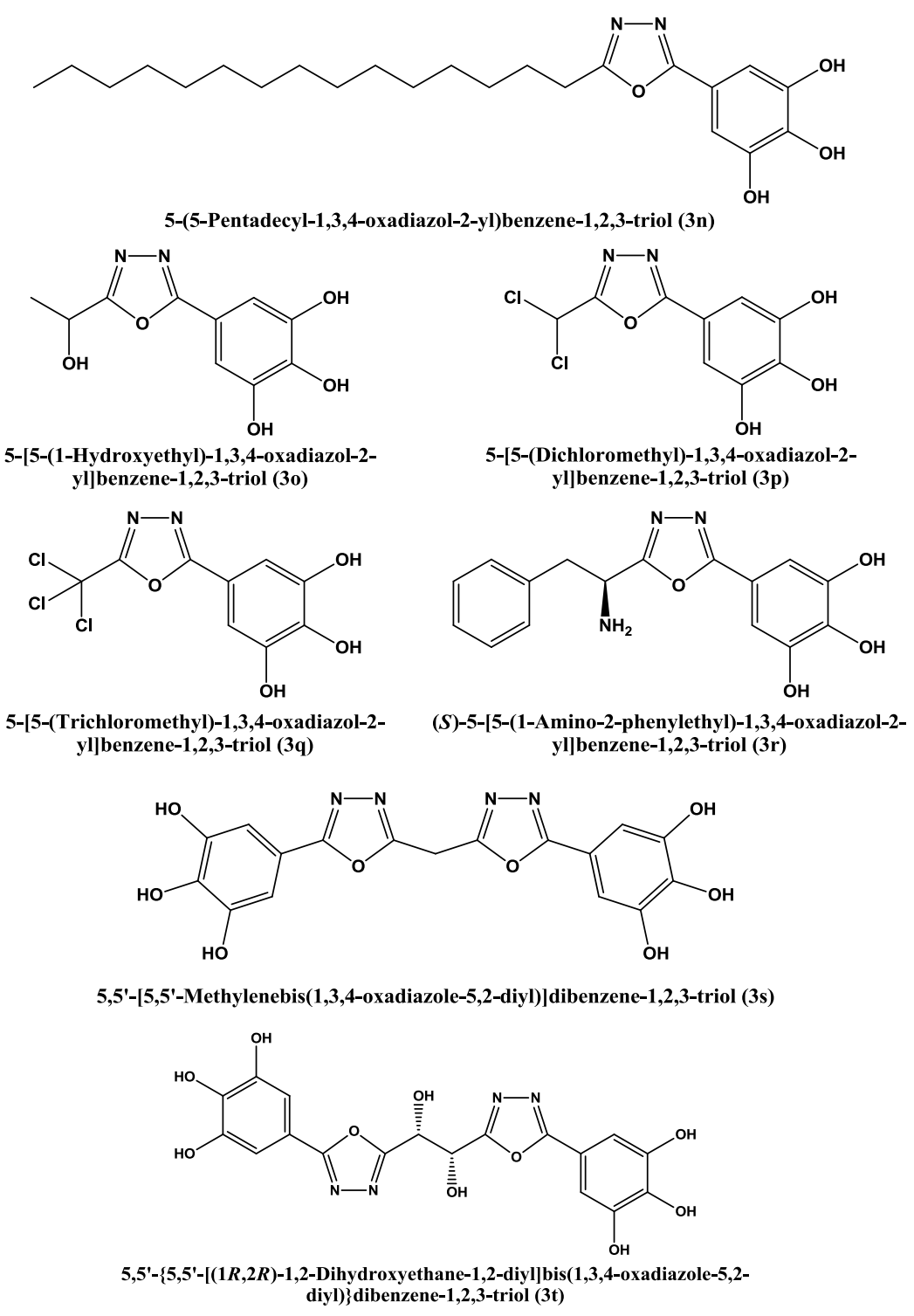


<smiles>Oc1cc(-c2nnc(CC(O)(Cc3nnc(-c4cc(O)c(O)c(O)c4)o3)c3nnc(-c4cc(O)c(O)c(O)c4)o3)o2)cc(O)c1O</smiles>

1,2,3-Tris[5-(3,4,5-trihydroxyphenyl)-1,3,4-oxadiazol-2-yl]propan-2-ol (3u)<smiles>Oc1cc(-c2nnc(/C=C/c3ccccc3)o2)cc(O)c1O</smiles>

(E)-5-(5-Styryl-1,3,4-oxadiazol-2-yl)benzene-1,2,3-triol (3v)<smiles>Oc1cc(-c2nnc(/C=C/c3nnc(-c4cc(O)c(O)c(O)c4)o3)o2)cc(O)c1O</smiles>

(E)-5,5'-[5,5'-(Ethene-1,2-diyl)bis(1,3,4-oxadiazole-5,2-diyl)] dibenzene-1,2,3-triol (3w) 
<smiles>Oc1cc(-c2nnc(-c3ccc(Br)cc3)o2)cc(O)c1O</smiles>

\section{5-[5-(4-Bromophenyl)-1,3,4-oxadiazol-2-yl]benzene-1,2,3-triol (3x)}<smiles>Oc1cc(-c2nnc(-c3cc(O)c(O)c(O)c3)o2)cc(O)c1O</smiles>

5,5'-(1,3,4-Oxadiazole-2,5-diyl)dibenzene-1,2,3-triol (3y)<smiles>Oc1cc(-c2nnc(-c3cnc4cc(Cl)ccc4c3O)o2)cc(O)c1O</smiles>

5-[5-(7-Chloro-4-hydroxyquinolin-3-yl)-1,3,4-oxadiazol-2-yl]benzene-1,2,3-triol (3z)<smiles>CCOC(=O)c1cc(O)c(O)c(O)c1</smiles>

Ethyl 3,4,5-trihydroxybenzoate (Ethyl gallate, $\mathbf{1 n z}$ )<smiles>NNC(=O)c1cc(O)c(O)c(O)c1</smiles> 


\section{Appendix B}

\section{Scanned Copy of the Elemental Analyses (Microanalyses of C, H, and N Contents) Results for}

\section{Compound 2nz \& Compounds 3n-z:}
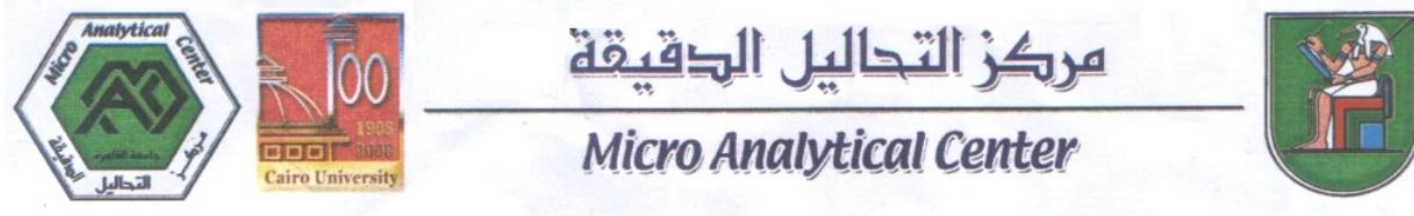

$$
\text { السبد الأستاذ الدكتور عميد كلية الصيدلة - جامعة المنصورة }
$$

أفيد سيادتكم علما بأن نتيجة التحاليل المرسلة من السيد / .د. أمجد محمد ربيع

Results of Analysis

\begin{tabular}{|c|c|c|c|c|c|c|c|}
\hline $\begin{array}{l}\text { Code } \\
\text { No }\end{array}$ & $\begin{array}{c}\text { Sample } \\
\text { No }\end{array}$ & $\mathrm{C}, \%$ & $\mathrm{H}, \%$ & $\mathrm{~N}, \%$ & $\mathrm{Br}, \%$ & $\mathrm{~S}, \%$ & Remarks \\
\hline \multirow[t]{14}{*}{24315} & $2 n z$ & 45.64 & 4.37 & 15.24 & & & \\
\hline & $3 n$ & 68.18 & 8.93 & 6.93 & & & \\
\hline & 30 & 50.46 & 4.24 & 11.73 & & & \\
\hline & $3 p$ & 39.01 & 2.18 & 10.10 & & & \\
\hline & $3 q$ & 34.77 & 1.61 & 8.95 & & & \\
\hline & $3 r$ & 61.39 & 4.80 & 13.41 & & & \\
\hline & $3 \mathrm{~s}$ & 51.09 & 3.03 & 14.04 & & & \\
\hline & $3 t$ & 48.48 & 3.14 & 12.53 & & & \\
\hline & $3 u$ & 50.96 & 3.16 & 13.21 & & & \\
\hline & $3 v$ & 64.80 & 4.09 & 9.49 & & & \\
\hline & $3 w$ & 52.47 & 2.92 & 13.57 & & & \\
\hline & $3 x$ & 48.12 & 2.63 & 8.06 & & & \\
\hline & $3 y$ & 52.91 & 3.15 & 8.76 & & $x=$ & \\
\hline & $3 z$ & 54.91 & 2.72 & 11.33 & & & \\
\hline
\end{tabular}

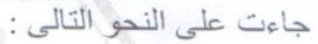

مدير مركز التحاليل الدقبقة

(1)

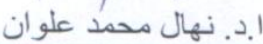

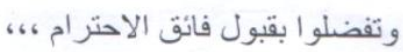

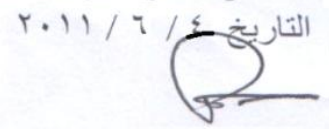




\section{REFERENCES}

[1] Halliwell, B. Antioxidants: The basics-what they are and how to evaluate them. Adv. Pharmacol. 1996, 38(Part I), 3-20

[2] Halliwell, B.; Gutteridge, J. M. C. Free Radicals in Biology and Medicine; $4^{\text {th }}$ Edition. Oxford University Press: New York, U.S.A., 2007.

[3] Diplock, A. T.; Charleux, J.-L.; Crozier-Willi, G.; Kok, F. J.; Rice-Evans, C.; Roberfroid, M.; Stahl, W.; Viña-Ribes, J. Functional food science and defence against reactive oxidative species. Br. J. Nutr. 1998, 80(Suppl. 1), S77-S112.

[4] Sies, H. Oxidative stress: Oxidants and antioxidants (in Physiological Society Symposium: Impaired endothelial and smooth muscle cell function in oxidative stress). Exp. Physiol. 1997, 82(2), 291-295.

[5] Emerit, J.; Edeas, M.; Bricaire, F. Neurodegenerative diseases and oxidative stress. Biomed. Pharmacother. 2004, 58(1), 39-46.

[6] Rahman, T.; Hosen, I.; Towhidul Islam, M. M.; Shekhar, H. U. Oxidative stress and human health. Adv. Biosci. Biotechnol. 2012, 3(7A), 997-1019, and references cited therein.

[7] Gilgun-Sherki, Y.; Melamed, E.; Offen, D. Oxidative stress induced-neurodegenerative diseases: The need for antioxidants that penetrate the blood brain barrier. Neuropharmacology 2001, 40(8), 959-975.

[8] Sheu, S.-S.; Nauduri, D.; Anders, M. W. Targeting antioxidants to mitochondria: A new therapeutic direction. Biochim. Biophys. Acta - Mol. Basis Dis. 2006, 1762(2), 256-265.

[9] Ng, F.; Berk, M.; Dean, O.; Bush, A. I. Oxidative stress in psychiatric disorders: Evidence base and therapeutic implications. Int. J. Neuropsychopharmacol. 2008, 11(6), 851-876.

[10] Pieczenik, S. R.; Neustadt, J. Mitochondrial dysfunction and molecular pathways of disease. Exp. Mol. Pathol. 2007, 83(1), 84-92.

[11] Kuloglu, M.; Atmaca, M.; Tezcan, E.; Gecici, Ö.; Tunckol, H.; Ustundag, B. Antioxidant enzyme activities and malondialdehyde levels in patients with obsessivecompulsive disorder. Neuropsychobiology 2002, 46(1), 27-32.

[12] Awasthi, D.; Church, D. F.; Torbati, D.; Carey, M. E.; Pryor, W. A. Oxidative stress following traumatic brain injury in rats. Surg. Neurol. 1997, 47(6), 575-582.

[13] Alwis, D. S.; Johnstone, V.; Yan, E.; Rajan, R. Diffuse traumatic brain injury and the sensory brain. Proc. Aust. Physiol. Soc. 2013, 44, 13-26.

[14] Kumar, S. V.; Saritha, G.; Fareedullah, M. Role of antioxidants and oxidative stress in cardiovascular diseases. Ann. Biol. Res. 2010, 1(3), 158-173.

[15] Pinchuk, I.; Lichtenberg, D. The mechanism of action of antioxidants against lipoprotein peroxidation, evaluation based on kinetic experiments. Prog. Lipid Res. 2002, 41(4),
279-314.

[16] Lakshmi, S. V. V.; Padmaja, G.; Kuppusamy, P.; Kutala, V. $\mathrm{K}$. Oxidative stress in cardiovascular disease. Indian $J$. Biochem. Biophys. 2009, 46(6), 421-440.

[17] Shinde, A.; Ganu, J.; Naik, P.; Sawant, A. Oxidative stress and antioxidative status in patients with alcoholic liver disease. Biomed. Res. 2012, 23(1), 105-108.

[18] Robles, L.; Vaziri, N. D.; Ichii, H. Role of oxidative stress in the pathogenesis of pancreatitis: Effect of antioxidant therapy. Pancreatic Disord. Ther. 2013, 3(1), 112.

[19] Herrling, T.; Jung, K.; Fuchs, J. The role of melanin as protector against free radicals in skin and its role as free radical indicator in hair. Spectrochim. Acta, Part A 2008, 69(5), 1429-1435.

[20] Franski, R. Biological Activities of the compounds bearing 1,3,4-oxa(thia)diazole ring. Asian J. Chem. 2005, 17(4), 2063-2075.

[21] De Oliveira, C. S.; Lira, B. F.; Barbosa-Filho, J. M.; Lorenzo, J. G. F.; de Athayde-Filho, P. F. Synthetic approaches and pharmacological activity of 1,3,4-oxadiazoles: A review of the literature from 2000-2012. Molecules 2012, 17(9), 10192-10231.

[22] Mehta, D. K.; Das, R. Synthesis and in vitro antioxidant activity of some new 2,5-disubstituted-1,3,4-oxadiazoles containing furan moiety. Int. J. Pharm. Sci. Res. 2011, 2(11), 2959-2963.

[23] Yang, C. S.; Lambert, J. D.; Sang, S. Antioxidative and anticarcinogenic activities of tea polyphenols. Arch. Toxicol. 2009, 83(1), 11-21.

[24] Pannala, A. S.; Chan, T. S.; O’Brien, P. J.; Rice-Evans, C. A. Flavonoid B-ring chemistry and antioxidant activity: Fast reaction kinetics. Biochem. Biophys. Res. Commun. 2001, 282(5), 1161-1168.

[25] Rice-Evans, C. A.; Miller, N. J.; Paganga, G. Structure-antioxidant activity relationships of flavonoids and phenolic acids. Free Radical Biol. Med. 1996, 20(7), 933-956.

[26] Takaoka, S.; Takaoka, N.; Minoshima, Y.; Huang, J.-M.; Kubo, M.; Harada, K.; Hioki, H.; Fukuyama, Y. Isolation, synthesis, and neurite outgrowth-promoting activity of illicinin A from the flowers of Illicium anisatum. Tetrahedron 2009, 65(40), 8354-8361, and references cited therein.

[27] Majumdar, K. C.; Chattopadhyay, B.; Shyam, P. K.; Pal, N. A new disc-shaped mesogenic compound with olefinic linkage derived from triphenylamine: Synthesis, mesogenic behavior and fluorescence properties. Tetrahedron Lett. 2009, 50(49), 6901-6905, and references cited therein.

[28] Ambika; Singh, P. P.; Chauhan, S. M. S. Chemoselective esterification of phenolic acids in the presence of sodium bicarbonate in ionic liquids. Synth. Commun. 2008, 38(6), 928-936.

[29] Dodo, K.; Minato, T.; Noguchi-Yachide, T.; Suganuma, M.; Hashimoto, Y. Antiproliferative and apoptosis-inducing activities of alkyl gallate and gallamide derivatives related to (-)-epigallocatechin gallate. Bioorg. Med. Chem. 2008, 16(17), 7975-7982.

[30] Łukasik, N; Wagner-Wysiecka, E. A review of amide bond 
formation in microwave organic synthesis. Curr. Org. Synth. 2014, 11(4), 592-604, and references cited therein.

[31] Zheng, X.; Li, Z.; Wang, Y.; Chen, W.; Huang, Q.; Liu, C.; Song, G. Syntheses and insecticidal activities of novel 2,5-disubstituted 1,3,4-oxadiazoles. J. Fluorine Chem. 2003, 123(2), 163-169.

[32] Chandrakantha, B.; Shetty, P.; Nambiyar, V.; Isloor, N.; Isloor, A. M. Synthesis, characterization and biological activity of some new 1,3,4-oxadiazoles bearing 2-fluoro-4-methoxyphenyl moiety. Eur. J. Med. Chem. 2010, 45(3), 1206-1210.

[33] Mathew, V.; Keshavayya, J.; Vaidya, V. P.; Giles, D. Studies on synthesis and pharmacological activities of 3,6-disubstituted-1,2,4-triazolo[3,4- $b]$-1,3,4-thiadiazoles and their dihydro analogues. Eur. J. Med. Chem. 2007, 42(6), 823-840.

[34] Amir, M.; Javed, S. A.; Kumar, H. Synthesis of some 1,3,4-oxadiazole derivatives as potential anti-inflammatory agents. Indian J. Chem. 2007, 46B(6), 1014-1019.

[35] Saha, A.; Kumar, R.; Kumar, R.; Devakumar, C. Development and assessment of green synthesis of hydrazides. Indian J. Chem. 2010, 49B(4), 526-531, and references cited therein.

[36] Demirbaş, N. Synthesis and characterization of new triheterocyclic compounds consisting of 1,2,4-triazol-3-one, 1,3,4-thiadiazole and 1,3,4-oxadiazole rings. Turk. J. Chem. 2005, 29(2), 125-133, and references cited therein.

[37] Kempe, G.; Bögel, M.; Roewer, G. Constitution and redox stability of copper(II)-complexes with substituted hydrazines. J. Prakt. Chem. (Leipzig) 1981, 323(3), 360-366, and references cited therein.

[38] Koufaki, M.; Kiziridi, C.; Alexi, X.; Alexis, M. N. Design and synthesis of novel neuroprotective 1,2-dithiolane/chroman hybrids. Bioorg. Med. Chem. 2009, 17(17), 6432-6441.

[39] Arunkumar, S.; Ilango, K.; Manikandan, R. S.; Sudha, M.; Ramalakshmi, N. Synthesis, characterisation and biological evaluation of some novel 2,5-disubstituted-1,3,4-oxadiazole derivatives of gallic acid. Int. J. ChemTech Res. 2009, 1(4), 1094-1099.

[40] Ilango, K.; Arunkumar, S. Synthesis, antimicrobial and antitubercular activities of some novel trihydroxybenzamidoazetidin-2-one derivatives. Trop. J. Pharm. Res. 2011, 10(2), 219-229.

[41] Mandal, S. K.; Saha, D.; Jain, V. K.; Jain, B. Synthesis and antitubercular activity of some triazole derivatives of propyl gallate. Int. J. Pharma Sci. Res. 2010, 1(11), 465-473.

[42] Mandal, S. K.; Saha, D.; Jain, B.; Jain, V. K. Synthesis, characterization and evaluation of antitubercular activity of some novel triazole derivatives of gallic acid. Int. J. Res. Pharm. Biomed. Sci. 2011, 2(1), 168-174.

[43] Mandal, S. K.; Saha, D.; Jain, V. K.; Jain, B. Synthesis, characterization and evaluation of antibacterial and antifungal activity of triazole derivatives of gallic acid. Int. J. Appl. Biol. Pharm. Technol. 2010, I(3), 1300-1311.

[44] Arunkumar, S.; Ilango, K.; Ravindar, B.; Ramalakshmi, N. Synthesis and biological evaluation of some novel triazolothiadiazole derivatives of gallic acid. Der Pharma Chem. 2009, 1(1), 70-77, and references cited therein.

[45] Arunkumar, S.; Ilango, K.; Manikandan, R. S.; Ramalakshmi, N. Synthesis and anti-inflammatory activity of some novel pyrazole derivatives of gallic acid. E-J. Chem. 2009, 6(S1), S123-S128.

[46] Ilango, K.; Arunkumar, S. Synthesis and antitubercular activity of novel thiazolidinone derivatives of gallic acid. $J$. Pharm. Res. 2011, 4(9), 3001-3003.

[47] Padmavathi, V.; Reddy, G. S.; Padmaja, A.; Kondaiah, P.; Ali-Shazia. Synthesis, antimicrobial and cytotoxic activities of 1,3,4-oxadiazoles, 1,3,4-thiadiazoles and 1,2,4-triazoles. Eur. J. Med. Chem. 2009, 44(5), 2106-2112.

[48] Gwaram, N. S.; Ali, H. M.; Abdulla, M. A.; Buckle, M. J. C.; Sukumaran, S. D.; Chung, L. Y.; Othman, R.; Alhadi, A. A.; Yehye, W. A.; Hadi, A. H. A.; Hassandarvish, P.; Khaledi, H.; Abdelwahab, S. I. Synthesis, characterization, X-ray crystallography, acetyl cholinesterase inhibition and antioxidant activities of some novel ketone derivatives of gallic hydrazide-derived Schiff bases. Molecules 2012, 17(3), 2408-2427.

[49] Gohil, V. M.; Agrawal, S. K.; Saxena, A. K.; Garg, D.; Gopimohan, C.; Bhutani, K. K. Synthesis, biological evaluation and molecular docking of aryl hydrazines and hydrazides for anticancer activity. Indian J. Exp. Biol. 2010, 48(3), 265-268, and references cited therein.

[50] Padmavathi, V.; Reddy, G. S.; Mohan, A. V. N.; Mahesh, K. Synthesis of symmetrical and unsymmetrical 1,3,4-oxadiazoles and their interconversion to 1,3,4-thiadiazoles and 1,2,4-triazoles. ARKIVOC (Gainesville, FL, U.S.) 2008, 2008(xvii), 48-60.

[51] Mahajan, A.; Pai, N. Simultaneous isolation and identification of phytoconstituents from Terminalia chebula by preparative chromatography. J. Chem. Pharm. Res. 2010, 2(5), 97-103.

[52] Silverstein, R. M.; Webster, F. X.; Kiemle, D. J. Spectrometric Identification of Organic Compounds; $7^{\text {th }}$ Edition. John Wiley \& Sons, Inc.: New York, U.S.A., 2005.

[53] Kumar, H.; Javed, S. A.; Khan, S. A.; Amir, M. 1,3,4-Oxadiazole/thiadiazole and 1,2,4-triazole derivatives of biphenyl-4-yloxy acetic acid: Synthesis and preliminary evaluation of biological properties. Eur. J. Med. Chem. 2008, 43(12), 2688-2698.

[54] Khan, M. T. H.; Choudhary, M. I.; Khan, K. M.; Rani, M.; Atta-ur-Rahman. Structure-activity relationships of tyrosinase inhibitory combinatorial library of 2,5-disubstituted-1,3,4-oxadiazole analogues. Bioorg. Med. Chem. 2005, 13(10), 3385-3395.

[55] Re, R.; Pellegrini, N.; Proteggente, A.; Pannala, A.; Yang, M.; Rice-Evans, C. Antioxidant activity applying an improved ABTS radical cation decolorization assay. Free Radical Biol. Med. 1999, 26(9-10), 1231-1237.

[56] Prouillac, C.; Vicendo, P.; Garrigues, J.-C.; Poteau, R.; Rima, G. Evaluation of new thiadiazoles and benzothiazoles as potential radioprotectors: Free radical scavenging activity in vitro and theoretical studies (QSAR, DFT). Free Radical Biol. Med. 2009, 46(8), 1139-1148, and references cited therein. 